NBER WORKING PAPER SERIES

\title{
HAZED AND CONFUSED: THE EFFECT OF AIR POLLUTION ON DEMENTIA
}

\author{
Kelly C. Bishop \\ Jonathan D. Ketcham \\ Nicolai V. Kuminoff \\ Working Paper 24970 \\ http://www.nber.org/papers/w24970 \\ NATIONAL BUREAU OF ECONOMIC RESEARCH \\ 1050 Massachusetts Avenue \\ Cambridge, MA 02138 \\ August 2018, Revised July 2022
}

We are grateful for insights and suggestions from Spencer Banzhaf, Richard Carson, Tatayana Deryugina, Olivier Deschenes, Katrina Jessoe, Michael Greenstone, David Kelly, Alan Krupnick, Daniel McFadden, Alvin Murphy, Laura Schechter, and seminar audiences at the AERE Summer meeting, the Annual Health Economics Conference, the ASHEcon conference, Society for Consumer Psychology Conference, the IHEA Congress, USC Health Economics conference, UC Santa Barbara Occasional Workshop, Arizona State University, Colorado School of Mines, Emory University, Georgia State University, London School of Economics, Oxford University, Resources for the Future, Tinbergen Institute, Tulane University, University of Arizona, University of Braga, UC Berkeley, UC Davis, UC San Diego, University of Chicago, University of Copenhagen, University of Kentucky, University of Wisconsin, Virginia Tech and Yale. The views expressed herein are those of the authors and do not necessarily reflect the views of the National Bureau of Economic Research.

NBER working papers are circulated for discussion and comment purposes. They have not been peer-reviewed or been subject to the review by the NBER Board of Directors that accompanies official NBER publications.

(C) 2018 by Kelly C. Bishop, Jonathan D. Ketcham, and Nicolai V. Kuminoff. All rights reserved. Short sections of text, not to exceed two paragraphs, may be quoted without explicit permission provided that full credit, including $(\odot)$ notice, is given to the source. 
Hazed and Confused: The Effect of Air Pollution on Dementia

Kelly C. Bishop, Jonathan D. Ketcham, and Nicolai V. Kuminoff

NBER Working Paper No. 24970

August 2018, Revised July 2022

JEL No. I18,Q53

\begin{abstract}
$\underline{\text { ABSTRACT }}$
We study whether long-term cumulative exposure to airborne small particulate matter ( $\left.\mathrm{PM}_{2.5}\right)$ affects the probability that an individual receives a new diagnosis of Alzheimer's disease or related dementias. We track the health, residential location, and $\mathrm{PM}_{2.5}$ exposures of Americans aged 65 and above from 2001 through 2013. The expansion of Clean Air Act regulations led to quasi-random variation in individuals' subsequent exposures to $\mathrm{PM}_{2.5}$. We leverage these regulations to construct instrumental variables for individual-level decadal $\mathrm{PM}_{2.5}$ that we use within flexible probit models that also account for any potential sample selection based on survival. We find that a $1 \mu \mathrm{g} / \mathrm{m} 3$ increase in decadal $\mathrm{PM}_{2.5}$ increases the probability of a new dementia diagnosis by an average of 2.15 percentage points. All else equal, we find larger effects for women, older people, and people with more clinical risk factors for dementia. These effects persist below current regulatory thresholds.
\end{abstract}

Kelly C. Bishop

Department of Economics

Arizona State University

PO Box 879801

Tempe, AZ 85287-9801

kelly.bishop@asu.edu

Jonathan D. Ketcham

Earl G. and Gladys C. Davis Distinguished

Research Professor in Business

Department of Economics

W.P. Carey School of Business

Arizona State University

300 E. Lemon Street

Tempe, AZ 85287-4106

ketcham@asu.edu
Nicolai V. Kuminoff

Department of Economics

Arizona State University

P.O. Box 879801

Tempe, AZ 85287

and NBER

kuminoff@asu.edu

A online appendix is available at http://www.nber.org/data-appendix/w24970 
Research shows that airborne particulate matter increases mortality. This effect persists around the world and over time, from the historically high exposures in London in the 1960s (McMillan and Murphy 2017) and China in the 2000s (Li et al. 2019) to the historically low exposures in the US in the 2000s (Deryugina et al. 2019). Research also shows that air pollution constrains the production and the productivity of human capital (Graff-Zivin and Neidell 2013). For instance, daily pollution spikes have been found to reduce students' scores on high-stakes exams (Ebenstein, Lavy, and Roth 2016). Among working-age adults, daily pollution spikes have been found to reduce performance of both manual and cognitive tasks (Chang et al. 2016, Archsmith, Heyes, and Saberian 2017). However, prior research has not applied causal methods to evaluate whether airborne particulate matter degrades human capital later in life apart from mortality.

Our study is the first to use a causal research design to evaluate whether longterm, later-in-life exposure to airborne small particulates (i.e., $\mathrm{PM}_{2.5}$, particulates smaller than 2.5 microns in diameter) plays a role in causing dementia. Medical research has documented associations between long-term, later-in-life exposure to $\mathrm{PM}_{2.5}$ specifically and the probability of individuals receiving a new dementia diagnosis, although as with other suspected causes of dementia, the precise mechanisms remain unknown (Peters et al. 2019, Underwood 2017, Block et al. 2012). Further, these associations may not be causal due to omitted variables, errors in measuring individuals' pollution exposures, or selection bias.

We develop a research design to account for potential biases due to prior residential sorting (driven by pollution, health, and/or preferences), measurement error in pollution, and selection on survival. Specifically, we estimate the effects of individuals' later-in-life exposure to $\mathrm{PM}_{2.5}$ for up to a decade, the longest duration of quasi-random variation available to us. This conditionally exogenous variation resulted from the Environmental Protection Agency's (EPA) expansion of the Clean Air Act (CAA). Based on air quality monitor readings from 2001-2003, the EPA 
began to enforce a maximum threshold on $\mathrm{PM}_{2.5}$, prompting local regulators to clean up polluted areas beginning in 2004. The regulatory incentives for cleanup were larger in nonattainment counties that exceeded the maximum threshold on $\mathrm{PM}_{2.5}$. The incentives caused differences within counties as well. As a result, individuals with the same $\mathrm{PM}_{2.5}$ exposures from 2001-2003 experienced different $\mathrm{PM}_{2.5}$ exposures over the next decade.

We use this individual-level variation from the EPA's nonattainment designations as instruments to identify how cumulative $\mathrm{PM}_{2.5}$ exposure from 2004-2013 affected the probability of receiving a new diagnosis of dementia during this period among Medicare beneficiaries age 65 and above who did not have dementia in 2004. Specifically, we use county nonattainment status flexibly interacted with individual-level PM $_{2.5}$ from 2001-2003 as instruments for the individual's cumulative $\mathrm{PM}_{2.5}$ exposure from 2004-2013. In addition to addressing bias from omitted variables, including genetics, earlier-in-life exposure, and other latent risk factors for dementia, our estimators also address the inevitable error in measuring an individual's pollution exposure.

We apply this design to thirteen years of individual-level data on a random sample of millions of Americans age 65 and above. These data track their diagnosis dates for many illnesses including Alzheimer's disease and related dementias, their demographics, and their sequence of residential addresses from 2001 through 2013. We use these residential addresses to link to measures of individual-level $\mathrm{PM}_{2.5}$ exposure using data from EPA air quality monitors.

We estimate year-specific probit models that allow for heterogeneity in the effects of $\mathrm{PM}_{2.5}$ across individuals and across exposure duration while flexibly controlling for individual characteristics associated with dementia risk, including race, gender-by-integer-age interactions, baseline medical expenditures, baseline exposure to $\mathrm{PM}_{2.5}$, fully interacted sets of baseline medical conditions, and the socioec- 
onomic composition of individuals' baseline neighborhoods (defined as a US Census block group). Further, we include Core-Based Statistical Area fixed effects to absorb spatial variation in diagnostic standards, health care quality and access, and latent environmental quality. Finally, we account for the fact that our main estimation sample is limited to individuals who survived through the model year following Heckman (1979). Specifically, we estimate the probability of survival in a separate first stage, using additional instruments constructed from data on individuals' diagnoses of cancers that, based on medical literature, are unrelated to dementia.

We find that a $1 \mu \mathrm{g} / \mathrm{m}^{3}$ increase in average $\mathrm{PM}_{2.5}$ concentrations increases the probability of receiving a new dementia diagnosis by the end of the decade by an average of 2.15 percentage points (pp). For reference, a $1 \mu \mathrm{g} / \mathrm{m}^{3}$ increase in average $\mathrm{PM}_{2.5}$ was $9.1 \%$ of the decadal mean and $59 \%$ of the decadal standard deviation during the period 2004-2013. The estimated marginal effects are larger at lower levels of $\mathrm{PM}_{2.5}$. We also find that the estimated marginal effects of $\mathrm{PM}_{2.5}$ increase with age, illness and duration of exposure, and that they are larger for women relative to men and larger for Black or African-American individuals relative to nonHispanic White individuals.

We conduct additional analyses to explore the possibility that nonattainment designations are conditionally associated with unobserved earlier-in-life factors that cause dementia, which would violate the exclusion restriction assumption of our instrumental variables. First, we estimate a model with dementia in 2004 as the outcome. The point estimate is negative, small in absolute value, and statistically indistinguishable from zero. This suggests that our model is unlikely to be confounded by unobserved differences in earlier-in-life or other factors that contribute to differences in dementia diagnoses and are conditionally associated with our instruments. Second, we evaluate other placebo health outcomes that may be linked to earlier-in-life factors but have no known link to $\mathrm{PM}_{2.5}$. We do not find a relation- 
ship between these placebo outcomes and individuals' cumulative $\mathrm{PM}_{2.5}$ exposures. ${ }^{1}$ Third, our results persist across a wide range of alternative modeling decisions including controlling for ancillary measures of air pollution exposure.

These findings indicate that air pollution's effects on dementia make its detriments to health and human capital substantially larger than previously realized. Incorporating these effects will be important for comprehensively evaluating the ongoing efforts to improve air quality worldwide.

\section{Later-in-Life PM2.5 Exposure and New Dementia Diagnoses}

\section{A. Existing Knowledge from the Medical Literature}

Recent research has documented a positive association between long-term cumulative exposure to fine-particulate air pollution later in life and dementia (Peters et al. 2019, Underwood 2017, Block et al. 2012). In addition, the literature has identified a number of potential pathways to explain this association, even if the details of the accumulation process remain yet unknown. Two physiological hallmarks of Alzheimer's disease specifically are the accumulation of tau protein and amyloid beta (Iaccarino et al. 2021), and recent research has established a link between this accumulation and $\mathrm{PM}_{2.5}$ exposure (Park et al. 2021). Research has also found relationships consistent with other potential neurological mechanisms underlying the link between $\mathrm{PM}_{2.5}$ and dementia and/or Alzheimer's disease (Alemany et al. 2021), including neuroinflammation caused by accumulation of $\mathrm{PM}_{2.5}$ in brain tissue (Kang et al. 2021, Maher et al. 2016), and associations between long-term, later-in-life exposure to $\mathrm{PM}_{2.5}$ and accumulated $\mathrm{PM}_{2.5}$ in the brain, smaller brain volume, and higher rates of brain infarcts or areas of necrosis and accelerated rates of brain atrophy, which is predictive of Alzheimer's disease (Younan et al. 2020, Wilker et al. 2015).

\footnotetext{
${ }^{1}$ In contrast, we find statistically significant positive effects for two outcomes with known links to $\mathrm{PM}_{2.5}$ (chronic obstructive pulmonary disease and chronic kidney disorder).
} 
Each of these potential pathways between cumulative $\mathrm{PM}_{2.5}$ exposure and a diagnosis of dementia are potentially moderated by a number of factors. These factors may include differences in $\mathrm{PM}_{2.5}$ chemical composition ( $\mathrm{Li}$ et al. 2021), earlier-inlife exposure, cardiovascular risk (Grande et al. 2020), and genetics. While less than half of the genetic factors that contribute to late-onset dementia have been identified (Ridge et al. 2016), recent research has found that genes play a role in moderating environmental factors' relationship to cognitive decline and dementia, including moderating the relationship between $\mathrm{PM}_{2.5}$ and dementia, specifically (Alemany et al. 2021, Kulick et al. 2020, Cacciottolo et al. 2017). ${ }^{2}$

\section{B. An Overview of our Research Design}

The medical literature described above, along with our data and policy setting, described in Sections II and III, respectively, inform several aspects of our research design. We preview this research design here.

We follow prior medical studies and assess the role of later-in-life, long-term exposure to $\mathrm{PM}_{2.5}$ as measured by single- or multiple-year annual average ambient concentrations in explaining new diagnoses of dementia (Wang et al. 2022, Li et al. 2022, Mortimais et al. 2021, Ran et al. 2021, Shi et al. 2021, Shi et al. 2020, Grande 2020, Cacciottolo et al. 2017). ${ }^{3}$ Specifically, we observe the timing of individuals' initial diagnosis (or lack thereof) and how it relates to thirteen years (2001-2013) of annual average exposure to $\mathrm{PM}_{2.5}$ for them individually based on their precise residential locations each year, allowing us to measure individual-specific exposure histories. ${ }^{4}$

\footnotetext{
${ }^{2}$ These issues make it difficult to allocate the shares of dementia cases due to genetic risk factors for dementia itself and due to environmental factors directly. Earlier research (e.g., Gatz et al. 1997) provided such shares under the strong assumption of additive separability between environmental factors and genetics.

${ }^{3}$ Like nearly all of the large-scale studies using secondary data, we cannot observe progression or severity of dementia over time. Clinical research commonly refers to this as "incident dementia" or "incidence of dementia". Peters et al. (2019) provides a review.

${ }^{4}$ Dementia is an absorbing state. Therefore, we model the occurrence of the initial diagnosis and exclude from our sample those who had been diagnosed previously.
} 
We depart from the prior medical literature by employing a causal research design to account for potential sources of confounding. Specifically, we observe quasi-random variation in individuals’ $\mathrm{PM}_{2.5}$ exposures beginning in 2004. As a result, we are able to model the effects of $\mathrm{PM}_{2.5}$ exposure across a full decade (20042013), conditional on baseline levels of $\mathrm{PM}_{2.5}$ (2001-2003).

In Section IV, we present a flexible probit model of how cumulative exposure to $\mathrm{PM}_{2.5}$ affects the probability of an individual receiving a new dementia diagnosis. We allow for heterogeneity by letting this effect vary flexibly with the level of cumulative $\mathrm{PM}_{2.5}$ exposure over the sample and with the levels of the other controls. We feature models using increasing durations of $\mathrm{PM}_{2.5}$ exposure. Finally, we include an extensive set of individual and neighborhood characteristics that may be correlated with new dementia diagnoses. These controls are described in detail in Section II.

Even with this extensive set of controls, identifying the effect of cumulative $\mathrm{PM}_{2.5}$ exposure on a new diagnosis of dementia presents several challenges. These include scope for measurement error in $\mathrm{PM}_{2.5}$ exposure, the potential for sorting on latent health, genetics, and earlier-in-life pollution exposures, and selection on survival. Our econometric approach, described in Section IV, is designed to account for each of these challenges.

First, to address measurement error in $\mathrm{PM}_{2.5}$ exposure and any geographic differentials in unobserved factors, we follow prior work (Chay and Greenstone 2005, Auffhammer, Bento, and Lowe 2009) and develop instrumental variables from the quasi-random variation in $\mathrm{PM}_{2.5}$ exposures (conditional on baseline) that was induced by the CAA regulations. Our control-function approach (Rivers and Vuong 1988) relies on the familiar assumptions of relevance and exogeneity for two-stage least squares. The policy environment and the variation-inducing CAA regulations are described in detail in Section III. 
Second, to address selection based on survival, we employ a selection-correction approach (Heckman 1979, Heckman and Robb 1986). To implement this approach, we use a set of additional instruments from the medical literature that are correlated with survival, but independent of the unobserved determinants of dementia. We also present a Lee (2009)-style bounds approach in Appendix H that does not rely on this additional set of instruments.

In addition, we consider the potential for sorting on genetics and omitted earlier-in-life factors. Prior research found that individuals' residential exposures to $\mathrm{PM}_{2.5}$ do not differ by APOE genotypes (Cacciotolo et al. 2017). In addition, Shin, Lillard, and Bhattacharya (2019) find "no correlation between Alzheimer's Disease polygenic risk score and net worth, housing assets and nonfinancial assets.” This indicates that dementia-related genetics are not associated with sorting into neighborhoods based on economic status. These studies provide evidence that genetic factors are unlikely to be correlated with our instrument. To test this directly, we examine the estimates of instrumented $\mathrm{PM}_{2.5}$ exposure on the presence of a dementia diagnosis by 2004. In addition to genetics, this assesses whether our results are likely to be explained by association between our instruments and any omitted earlier-in-life factors including other clinical risk factors, prior exposure to $\mathrm{PM}_{2.5}$, or different chemical compositions of $\mathrm{PM}_{2.5}$.

\section{Data and Measures}

\section{A. Medicare Data and Sample}

The US Medicare program provides universal health insurance for citizens over age 65. ${ }^{5}$ The US Centers for Medicare and Medicaid Services (CMS) maintains a comprehensive national database on beneficiaries, including their addresses at each

\footnotetext{
${ }^{5}$ We analyze "traditional” Medicare (TM) administrative records from CMS. CMS manages and pays claims for services provided to TM enrollees. Beneficiaries can opt out of TM and enroll in a private Medicare Advantage (MA) managed care plan. MA enrollees are left out of most studies of Medicare because MA plans historically did not report claims to CMS. We are able to overcome these limitations and include MA enrollees in some specifications described in Appendix J2.
} 
point in time, medical claims and diagnoses, and demographics. We track individuals from as early as 1999 through the end of $2013 .{ }^{6}$ Our featured estimation sample starts with a random 20\% sample of all traditional Medicare beneficiaries who were 65 and older on January 1, 2004. We then limit our sample to those who lived in counties with $\mathrm{PM}_{2.5}$ monitors, and for whom we can observe their health and residential locations. ${ }^{7}$

\section{B. Measuring dementia and its risk factors}

CMS's Chronic Conditions Data Warehouse (CCW) files use codes on Medicare insurance claims to track if and when each individual is diagnosed with specific chronic medical conditions. A dementia diagnosis is based on the presence of multiple symptoms of cognitive impairment that significantly impact daily functioning. ${ }^{8}$ Examples include memory loss, impaired judgement, loss of spatial awareness, depression, and behavioral changes. Alzheimer's Disease is the primary type of dementia, accounting for $60 \%$ to $80 \%$ of all cases. Our claims-based approach to identifying dementia diagnoses is well validated (Lee et al. 2019).

Figure I shows how the fraction of individuals diagnosed with dementia in Medicare data varies with age and gender in 2013. Diagnosis rates increase gradually with age through the mid-seventies before accelerating in the late seventies and beyond. The diagnosis rate is higher for women, and this gender gap widens with age. Conditional on age, diagnosis rates also differ by race. Diagnosis rates are generally higher for people denoted by CMS as "Black or African-American” and lower for “Asian/Pacific Islander” relative to "Hispanic” or “non-Hispanic White”. We account for this heterogeneity by creating a vector of demographics, denoted

\footnotetext{
${ }^{6}$ Due to the provenance of our data, we complement the random $20 \%$ sample with an independent, random $20 \%$ sample of those also age 65 by January 1, 2004 who purchased standalone prescription drug insurance plans through Medicare Part D at any point between 2006 and 2010 without the aid of low-income subsidies.

${ }^{7}$ We provide additional details about sample cuts and data definitions in Appendix A.

${ }^{8}$ The ICD-10 defines Alzheimer's disease (G30) as "A degenerative disease of the brain characterized by the insidious onset of dementia. Impairment of memory, judgment, attention span, and problem solving skills are followed by severe apraxias and a global loss of cognitive abilities. The condition primarily occurs after age 60 , and is marked pathologically by severe cortical atrophy and the triad of senile plaques; neurofibrillary tangles; and neuropil threads.”
} 
$X_{i}$. This vector includes race code indicators and indicators for each of the 52 possible sex-by-integer-age combinations from age 75 through 100 in $2013 .^{9}$

Figure I: DEMENTIA DiAgnOSIS BY AGE AND GENDER IN 2013

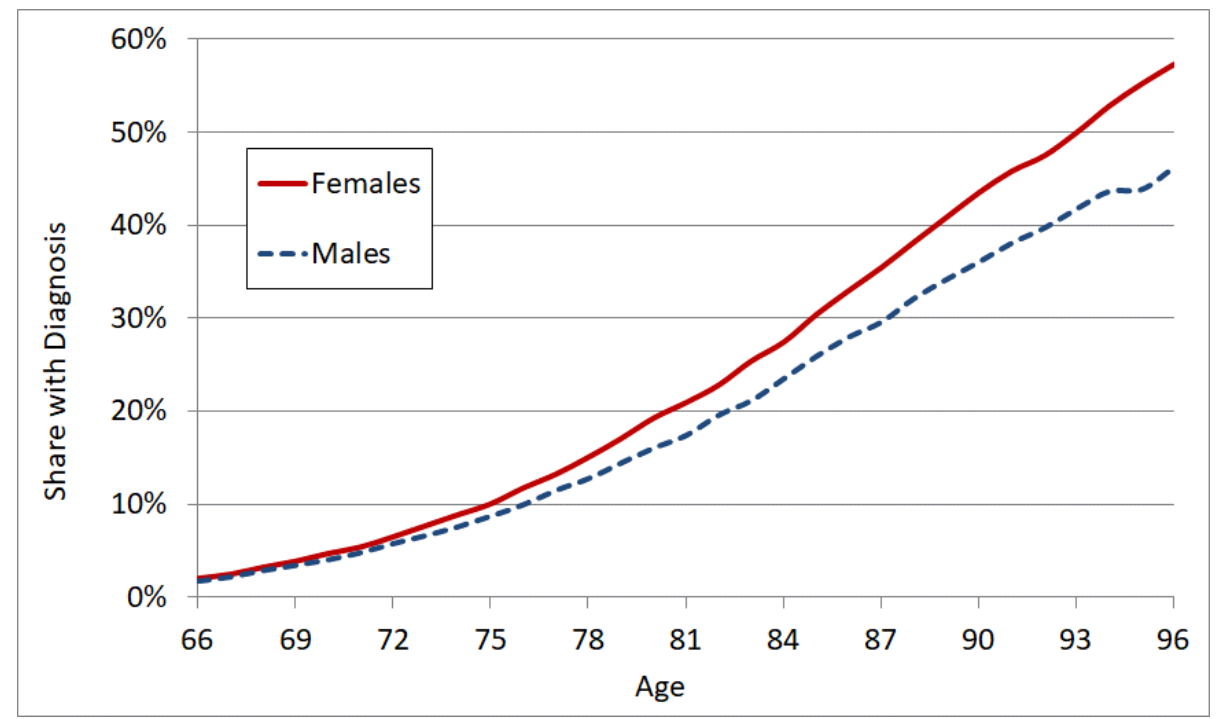

We further utilize the administrative CCW files to measure clinical risk factors. Specifically, we create a vector of health characteristics, denoted $H_{i}$. This includes indicators for whether the individual in 2004 had each one of the 32 possible combinations of hypertension, diabetes, congestive heart failure, ischemic heart disease, and stroke. These are the known diagnostic risks for dementia (Alzheimer's Association 2019). We further measure baseline health by including in $H_{i}$ a fourth-order polynomial function of total expenditures on all services covered by Medicare Parts $\mathrm{A}$ and $\mathrm{B}$ in $2004 .^{10}$

US Census data provide socioeconomic characteristics of the Census block group where the individual lived in 2004 according to CMS records. ${ }^{11}$ We define

${ }^{9} 75$ is the minimum age in 2013 within our estimation sample because that sample is limited to people who were 65 or older on January 1, 2004. Centenarians are grouped into two gender-specific bins because their small numbers prevent us from precisely estimating age-specific coefficients. Our results are unaffected by adding age-specific bins beyond age 100 .

${ }^{10}$ Medicare Parts A and B cover virtually all medical services aside from prescription drugs and long-term care. This includes doctors' services, preventive care, durable medical equipment, hospital outpatient services, laboratory tests, imaging, hospital inpatient services, nursing facilities, and hospice care.

${ }^{11}$ A block group contains 600 to 3,000 residents on average (US Census). 
neighborhood as the individual's Census block group and create a vector of neighborhood characteristics, denoted $W_{i}$. This vector includes median household income, per-capita income, mean and median house value, median rent, median house age, fractions of the housing stock that are owner occupied, renter occupied, and vacant, fraction of residents over age 65, fractions of residents who report being white, black, and Hispanic, and the fractions of residents in each of seven educational-attainment bins. These variables account for non-clinical factors associated with different risks of dementia. Appendix Table A1 provides summary statistics for each of the variables represented in $X_{i}, H_{i}$ and $W_{i}$.

Finally, we create indicators (denoted $C_{i, t}$ ) for the geographic regions where individuals lived in each year of our model. Specifically, we include 977 indicators for the US Census Bureau's Core-Based Statistical Areas (CBSAs) and the nonCBSA rural areas of each state. ${ }^{12}$ In our model, these indicators will absorb the effects of otherwise unobserved factors. First, they help to absorb any effects of residential sorting across CBSAs on the basis of latent risk factors for dementia. Second, they help to absorb the effects of environmental factors that could be spatially correlated with both $\mathrm{PM}_{2.5}$ and dementia, e.g., the presence of lead pipes or extreme temperatures which may cause morbidities that are risk factors for dementia. Third, they absorb all differences between geographic areas in health care delivery that might contribute to differences in diagnostic decisions, including patients’ access to medical care and physicians’ treatment styles.

\section{Measuring PM 2.5 Exposure}

In 1997, the EPA established monitoring protocols for $\mathrm{PM}_{2.5}$, and by 1999, an initial national network of regulatory-grade $\mathrm{PM}_{2.5}$ monitors was put into place. We use annual average $\mathrm{PM}_{2.5}$ concentrations recorded at each of these monitors from

\footnotetext{
12 There are 927 CBSAs in the US, which are defined by the Office of Management and Budget as of one or more counties anchored by an urban center of at least 10,000 people plus adjacent counties that are socioeconomically tied to the urban center by commuting. For people living outside of CBSAs, we create an additional 50 state-specific, rural dummy variables.
} 
2001 through 2013. We use data from a balanced panel of 485 monitors that operated continuously through our study period to avoid measurement error that could be introduced if new monitors tend to be located in more or less polluted areas (Grainger and Schreiber, 2019). ${ }^{13}$ In a sensitivity check, we instead use data from all 1,722 monitors.

We measure an individual's exposure to $\mathrm{PM}_{2.5}$ in year $t, P M 2.5_{i, t}$, based on concentrations at their residential address in that year. The CMS data include ZIP+4 Codes for each individual's sequence of addresses from 2004 to $2013 .{ }^{14}$ We use this information to measure the individual's cumulative exposure to $\mathrm{PM}_{2.5}$ incorporating changes in $\mathrm{PM}_{2.5}$ experienced as a result of moving. ${ }^{15}$ Individuals in our data live in 2.7 million distinct ZIP+4 Codes during 2004-2013. We use the latitude and longitude coordinates of each monitor and each ZIP+4 to assign the annual average concentration at each residence. ${ }^{16}$ Specifically, we calculate the geographical distance between each ZIP+4 centroid and each monitor. Then, for each centroid-year combination, we calculate a weighted average of concentrations recorded at all monitors with the weights given by the square of the inverse distance. ${ }^{17}$ Thus, as the distance from a ZIP+4 centroid to a monitor increases, the weight assigned to that monitor decreases.

\footnotetext{
${ }^{13}$ Following the literature, we drop individuals living in unmonitored counties. See Appendix A for details.

${ }^{14} \mathrm{ZIP}+4$ Codes are close to street addresses in terms of spatial precision: each code corresponds to a single mail delivery point such as a house, one floor of an apartment building, or one side of a street on a city block.

${ }^{15} 31 \%$ of individuals in our data move at least once, $17 \%$ move between counties and $10 \%$ move between states. These rates are similar to those reported by the Census Bureau for individuals aged 65 and above. We are unable to observe seasonal migration by people with more than one residence because we only observe the residential address on record with CMS. Fortunately, the scope for measurement error is small. Jeffery (2015) estimates that seasonal migrators only account for $2 \%$ to $4.1 \%$ of the Medicare population based on addresses on Medicare claims for primary care and emergency room visits.

${ }^{16}$ Geographic coordinates of ZIP+4 centroids were purchased from GeoLytics, which created them from the Census Bureau's TIGER/line Shapefiles and US Postal Service records.

${ }^{17}$ This method of interpolation, with weights given by the distance raised to a negative exponent, is a predominant method in the environmental economics literature.
} 
Figure II: AVERAge Residential ConCEntration of PM2.5 BY YeAR

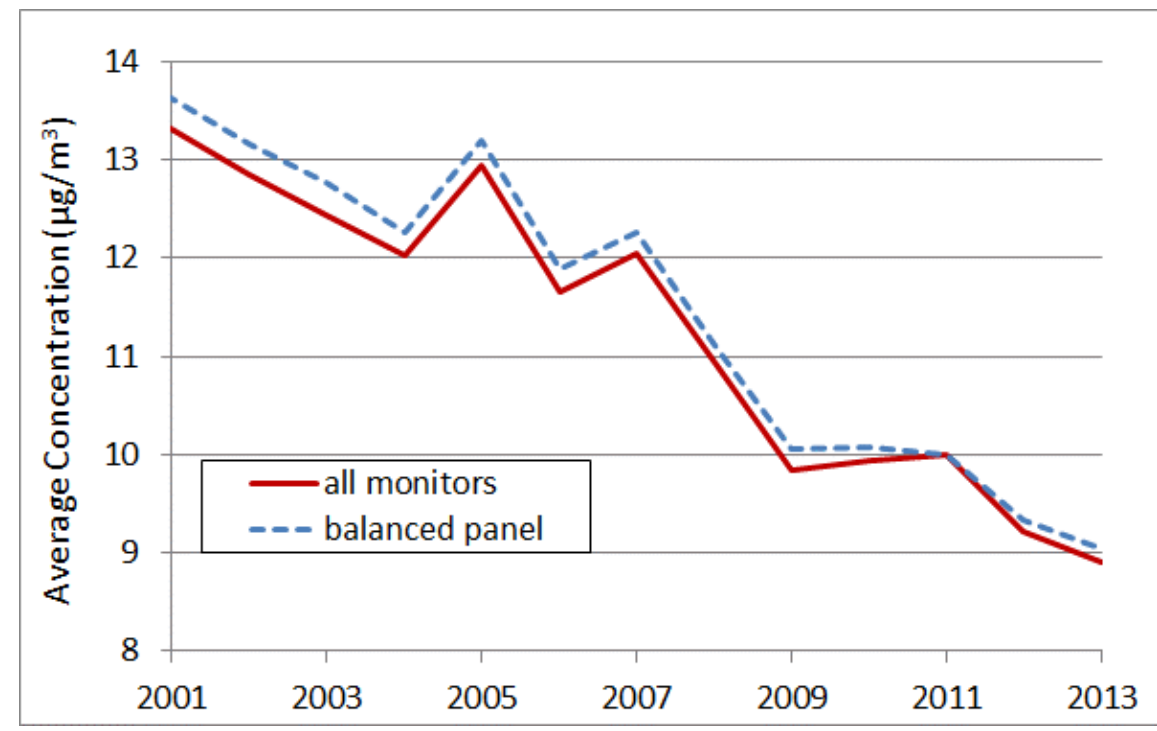

Note: The figure reports the annual average concentrations of fine particulate matter based on place of residence for people age 65 and above on Medicare.

Figure II shows that annual average concentrations of $\mathrm{PM}_{2.5}$ at the residences of the US Medicare population declined substantially during the 2000s, from over $13 \mu \mathrm{g} / \mathrm{m}^{3}$ (micrograms per cubic meter of air) in 2001 to about $9 \mu \mathrm{g} / \mathrm{m}^{3}$ in 2013. This is true regardless of whether we measure exposure using the balanced panel of monitors (the dashed line) or the full set of monitors (solid line).

We denote our measure of interest, the individual's average cumulative exposure to $\mathrm{PM}_{2.5}$ from 2004 to year $t$, as $\operatorname{durP} M_{i, t}$. We construct it by combining the described ZIP+4-specific annual PM $_{2.5}$ concentrations with individuals' residential ZIP+4 histories from 2004 to $t$ according to: $\operatorname{dur} P M_{i, t}=\sum_{s=2004}^{t} \frac{P M 2.5_{i, s}}{t-2004}$. Finally, we create a measure of the baseline $\mathrm{PM}_{2.5}$ concentrations at the locations where individuals lived in 2004. We denote this measure as base $P M_{i}$ and construct it as the average concentration over the three years 2001 to 2003. These three years are the years that the EPA based its nonattainment designations on, as discussed in the next section. 


\section{Clean Air Act Regulation of PM2.5}

The Clean Air Act (CAA) of 1970 established national standards for concentrations of regulated air pollutants. The EPA designated counties containing monitors that exceeded these standards as nonattainment. States with nonattainment counties were required to coordinate with local regulators to bring those counties into compliance with the standards. States that failed to bring their counties into attainment faced penalties including loss of federal highway funds.

Due to its pernicious effects on human health, particulate matter has been subject to sustained and evolving federal regulation (US EPA 2005). Beginning in 1971, the EPA regulated total suspended particulates (TSP). In light of evidence that health effects were driven by the smallest particulates, the EPA replaced the TSP standard with a standard on $\mathrm{PM}_{10}$ (particulates smaller than 10 microns in diameter) in 1987 and a standard on $\mathrm{PM}_{2.5}$ in 1997. Each new standard was followed by new nonattainment designations. These designations have the ability to affect

pollution in both nonattainment and attainment counties because pollution travels across county boundaries. However, the designations for particulate matter have induced relatively larger pollution reductions in nonattainment counties. Prior research used the TSP standard (Chay and Greenstone 2005, Isen, Rossin-Slater, and Walker 2017) and the $\mathrm{PM}_{10}$ standard (Bento, Friedman, and Lang 2015) to create instruments for TSP and $\mathrm{PM}_{10}$ exposures, respectively. In this paper, we use the $\mathrm{PM}_{2.5}$ standard to develop instruments for $\mathrm{PM}_{2.5}$ exposures.

In 1997, the EPA set the regulatory standard for average annual $\mathrm{PM}_{2.5}$ concentrations at $15.05 \mu \mathrm{g} / \mathrm{m}^{3}$. In April 2003, state and local regulators were given a February 2004 deadline to provide $\mathrm{PM}_{2.5}$ monitor data from the years 2001-2003, and to self-report any nonattainment monitors to the EPA, where nonattainment was defined by the monitor's three-year average $\mathrm{PM}_{2.5}$ concentrations from 2001-2003. Based on these reports, the EPA formally defined each monitored county to be in 
attainment or nonattainment in January $2005 .{ }^{18}$ For counties with multiple monitors, the designations were based on the monitor with the highest three-year average from 2001-2003.

We define 2004 as the start of the regulatory period because local regulators learned which counties would be nonattainment between April 2003, when they received the EPA's request for data, and February 2004, when they were required to submit their status. EPA monitor data show $\mathrm{PM}_{2.5}$ concentrations declining at a similar rate in both attainment and nonattainment counties prior to 2004, and then declining at a faster rate in nonattainment counties after 2004. These trends, shown in Appendix Figure C1, are analogous to the evidence that Chay and Greenstone (2005) first presented on the validity of using CAA regulation of PM as a quasiexperiment.

Figure III provides the intuition for how we use county nonattainment designations to isolate quasi-random variation in individuals' average $\mathrm{PM}_{2.5}$ exposures from 2004-2013, conditional on baseline concentrations from 2001-2003. ${ }^{19}$ The nonattainment and attainment lines plot the coefficients obtained by regressing the individual-level measure of decadal $\mathrm{PM}_{2.5}$ exposure, $\operatorname{dur} P M_{i, 2013}$, on indicators for

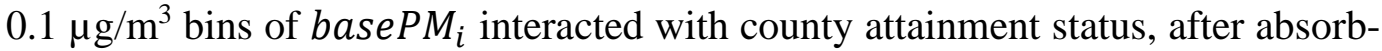
ing CBSA dummies. Comparing the nonattainment and attainment lines with the 45-degree line shows that post-regulatory reductions in $\mathrm{PM}_{2.5}$ were larger, on average, for individuals with larger baseline concentrations. This pattern is consistent with prior studies that used CAA regulatory standards to develop instruments for particulate matter exposures.

\footnotetext{
${ }^{18}$ Appendix Figure B1 shows the locations of attainment and nonattainment counties with air quality monitors. In 2005, 132 of the monitored counties containing approximately $27 \%$ of the US population were classified as nonattainment. Another 528 counties containing $43 \%$ of the US population were classified as attainment. The remaining counties lacked monitoring data and were designated "unclassifiable" and not subjected to additional regulation. Appendix Figure B2 shows the location of the monitors.

${ }^{19}$ As noted in Chay and Greenstone (2005), attainment status doesn't induce quasi-random variation in pollution levels, but rather quasi-random variation in changes in pollution. Equivalently, in our case, attainment status induces quasi-random variation in decadal pollution exposure, conditional on pre-regulatory baseline pollution.
} 
Figure III: Post-Regulatory PM 2.5 EXPOSURe 2004-2013, By CounTy AtTAinMENT STATUS AND PRE-REGULATORY EXPOSURE 2001-2003

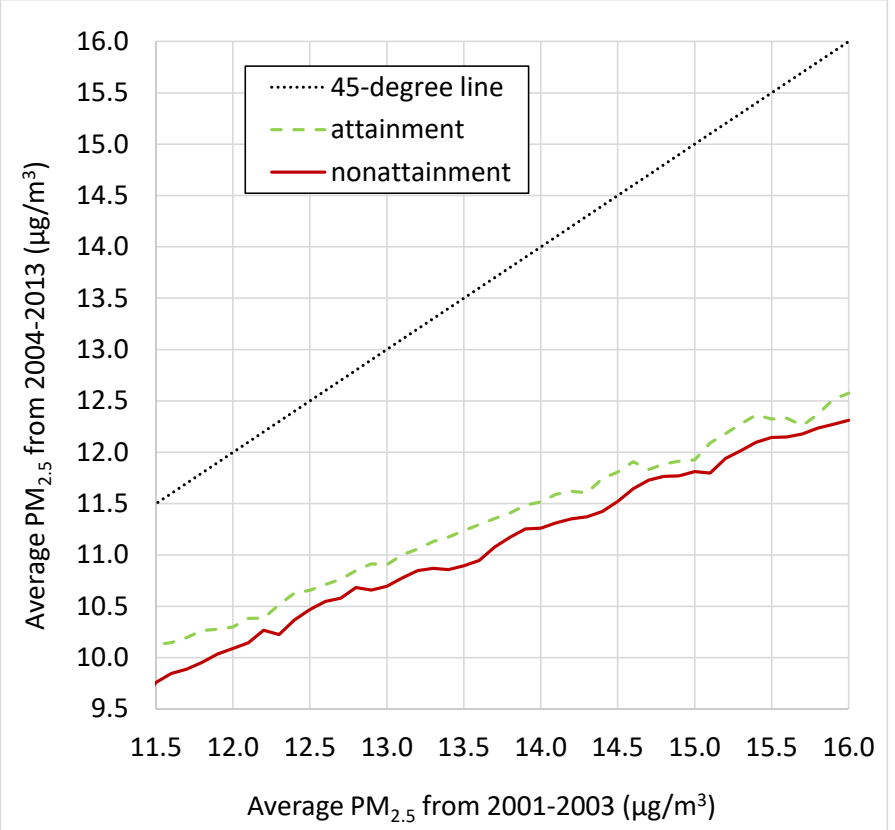

Note: The nonattainment and attainment lines represent estimates from regressing individual exposure from 2004-2013 on indicators for $0.10 \mu \mathrm{g} / \mathrm{m}^{3}$ bins of baseline exposure from 2001-2003 interacted with county attainment status. Additional covariates include CBSA dummies.

The key insight from Figure III is that the nonattainment line lies below the attainment line for all levels of average $\mathrm{PM}_{2.5}$ from 2001-2003. This difference is statistically significant at the $1 \%$ level. This shows that when we compare individuals in the same CBSA who were in the same residential $\mathrm{PM}_{2.5}$ bin for pre-regulatory exposure (2001-2003), those who lived in nonattainment counties were subsequently exposed to lower $\mathrm{PM}_{2.5}$ during 2004-2013 than those in attainment counties. This follows from the incentives that regulators faced to target their mitigation efforts at nonattainment counties (Chay and Greenstone's 2005, Isen, RossinSlater, and Walker 2017). In addition, the vertical distance between the nonattainment and attainment lines decreases with baseline $\mathrm{PM}_{2.5}$ concentrations from 2001- 
2003. ${ }^{20}$ This follows from the EPA policy in which a county's attainment status is linked to its dirtiest monitor, thus incentivizing local regulators to target pollution "hot spots” (Auffhammer, Bento, and Lowe 2009, Bento, Freedman, and Lang 2015).

\section{Estimating the Causal Impact of Decadal PM2.5 on Dementia}

We model how cumulative exposure to $\mathrm{PM}_{2.5}$ over the decade from 2004 to 2013 affects the probability of an individual receiving a new dementia diagnosis. First, we consider a contemporaneous, decadal model where the decade is treated as a single time period. Second, we extend this framework to instead aggregate cumulative, year-specific impacts over the decade.

\section{A. A Decadal Model of New Dementia Diagnoses}

Let $y_{i, t}$ indicate whether individual $i$ has received a dementia diagnosis by the end of year $t$ and let $\Delta y_{i}=y_{i, 2013}-y_{i, 2004}$ denote the change in dementia status between 2004 and 2013. Because dementia has no cure, it is an absorbing state and, by definition, $\Delta y_{i}$ is equal to zero for anyone with dementia in 2004. Therefore, we model whether individual $i$ is newly diagnosed with dementia by the end of 2013, conditional on having not received a dementia diagnosis before the end of $2004 .^{21}$

We model a new dementia diagnosis using a probit model where $\Delta y_{i}^{*}$ denotes the latent propensity to become newly diagnosed with dementia,

$$
\Delta y_{i}^{*}=h\left(\operatorname{durP} M_{i, 2013} ; \alpha_{i}\right)+\eta_{i},
$$

and where an individual is diagnosed with dementia if their latent propensity is positive, i.e., $\Delta y_{i}=1\left[\Delta y_{i}^{*}>0\right]$.

\footnotetext{
${ }^{20}$ The scaling of the vertical axis in Figure III makes this trend hard to discern. It is easier to discern in Figure IV. Fitting a linear trend to the vertical distance between the nonattainment and attainment lines in Figure III reveals that a $1 \mu \mathrm{g} / \mathrm{m}^{3}$ increase in baseline exposure is associated with a $0.02 \mu \mathrm{g} / \mathrm{m}^{3}$ reduction in the vertical distance between the lines.

${ }^{21}$ We begin with a model of new diagnosis of dementia, which is standard in clinical research on dementia. In principle, we could instead begin with a model describing an individual's dementia status in both 2004 and 2013 to derive Equation (1) below. Such a model is shown in Appendix G. Our discussion of identification below explicitly accounts for the fact that the error in Equation (1) captures changes in unobserved dementia determinants, conditional on not having dementia in 2004.
} 
The parameter of interest, $\alpha_{i}$, represents the causal effect of decadal exposure to $\mathrm{PM}_{2.5}$ on $\Delta y_{i}^{*}$, holding all other factors constant. ${ }^{22}$ All other factors that determine $\Delta y_{i}^{*}$ are denoted by the error $\eta_{i}$. Following Angrist and Pischke (2009), we decompose $\eta_{i}$ into a linear function of observable controls, $X_{i}, H_{i}, W_{i}, C_{i}$, basePM $M_{i}$, and an error, $e_{i}$ :

$$
\eta_{i}=\beta_{x} X_{i}+\beta_{H} H_{i}+\beta_{W} W_{i}+\beta_{C} C_{i, 2013}+f\left(\text { basePM }_{i} ; \beta_{\text {basePM }}\right)+e_{i} .
$$

Combining the two previous equations yields our equation of interest:

$$
\begin{aligned}
& \Delta y_{i}^{*}=h\left(d u r P M_{i, 2013} ; \alpha_{i}\right)+\beta_{x} X_{i}+\beta_{H} H_{i}+\beta_{W} W_{i}+\beta_{C} C_{i, 2013}+ \\
& f\left(\text { basePM }_{i} ; \beta_{\text {basePM }}\right)+e_{i}
\end{aligned}
$$

In the simplest specification of this model, we specify $h\left({\left.\operatorname{dur} P M_{i, 2013} ; \alpha_{i}\right)=}\right.$ $\alpha \operatorname{dur} P M_{i, 2013}$. In a more flexible specification of the decadal model, discussed in Section IV.B, we allow for non-linearities and heterogeneity along observable dimensions in the impact of $\operatorname{dur} P M_{i, 2013}$ on the probability of a new diagnosis of dementia. In Section IV.C, we present a model that allows for additional non-linearity and heterogeneity with respect to the duration of exposure to $\mathrm{PM}_{2.5}$.

We use $\alpha$ together with the other model parameters to recover the average marginal effect (AME) of changes in $\operatorname{dur} P M_{i, 2013}$ on the probability of a new diagnosis, $\operatorname{Prob}\left(\Delta y_{i}=1\right)$. We discuss the controls, $X, H, W, C$, base $P M$, and the error, $e$, in the following paragraphs.

In Section II, we defined the vectors of controls $X, H, W$, and $C$. The vector $X_{i}$ includes indicators for race and gender specific indicators for each integer age. $H_{i}$ includes indicators for each unique combination of pre-existing clinical risk-factors for dementia (hypertension, diabetes, congestive heart failure, ischemic heart disease, and stroke) and a fourth-order polynomial function of individual medical

\footnotetext{
${ }^{22}$ Epidemiological "stress" models that consider life histories are discussed in Deaton and Paxson (1998).
} 
spending in 2004. $W_{i}$ includes Census block group variables describing the socioeconomic characteristics of individuals living in individual i's neighborhood in 2004. Finally, $C_{i, 2013}$ is a vector of indicators for each individual's 2013 CBSA.

The final control is a fourth-order polynomial function, $f(\cdot)$, of baseP $_{i}$. This controls for any residual effects of pre-regulatory sorting into more polluted neighborhoods by individuals who are more likely to receive a future dementia diagnosis.

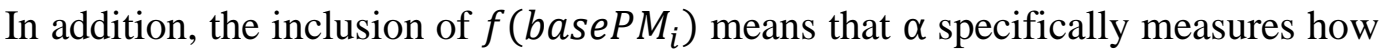
cumulative $\mathrm{PM}_{2.5}$ exposure from 2004 to 2013 affects the probability of a new dementia diagnosis, conditional on pre-regulatory, baseline concentrations.

Finally, $e_{i}$, is an error term that represents any other determinants of a new dementia diagnosis that are not controlled for by a linear function of $X_{i}, H_{i}, W_{i}, C_{i, 2013}$, and $f\left(\right.$ base $\left.P M_{i}\right)$. The model imposes no assumption about the relationship between our variable of interest, $\operatorname{dur} P M_{i, 2013}$, and $e_{i}{ }^{23}$ In fact, $e_{i}$ most likely contains factors that would lead it to be correlated with $\operatorname{dur} P M_{i, 2013}$, coming from (i) omitted variables, (ii) measurement error, and (iii) factors related to selection.

One example of an omitted variable in $e_{i}$ that may be correlated with $\operatorname{dur} P M_{i, 2013}$ is earlier-in-life exposure. While we don't specify the direct impact of earlier-in-life $\mathrm{PM}_{2.5}$ exposure, we allow for earlier-in-life exposure to affect new dementia diagnoses and to be correlated with $\operatorname{dur} P M_{i, 2013} \cdot{ }^{24}$ Another example is latent health. If individuals had sorted on unobserved health factors, including genetics, the error term and $\operatorname{dur} P M_{i, 2013}$ may be correlated. Like earlier-in-life exposure, we will not specify the direct impacts of these latent health measures, but we do not rule out their presence in $e_{i}$.

Measurement error in $\operatorname{dur} P M_{i, 2013}$ could also be present in $e_{i}$. All large-scale

\footnotetext{
${ }^{23}$ We make an assumption in Section IV.B regarding the independence of $e_{i}$ and the vector of controls and instruments.

${ }^{24}$ Because we allow prior exposure to be an element of the error term, rather than explicitly model its impact, we cannot answer questions directly related to lifetime exposure. In our model, $\alpha$ captures the causal effect of later-in-life decadal pollution on the probability of a new dementia diagnosis, holding all else constant, including earlier-in-life exposure.
} 
data on air pollution are based on ambient measures, such as satellite imaging or government monitors. While the regulatory-grade monitors that we use are wellvalidated, each one only measures pollution at a single place. ${ }^{25}$ As a result, all available measures of pollution likely differ from what individuals actually breathe. This can arise from individual differences in indoor air, daily mobility, and activities, or from the interpolation between geography-based measures required to develop individual-level measures.

Finally, new dementia diagnoses are only measured for those individuals who survive until the end of the model's time period. This could induce a correlation between $\operatorname{dur} P M_{i, 2013}$ and $e_{i}$ among survivors if latent health that determines survival is (conditionally) correlated with latent health that affects the probability of a new dementia diagnosis.

\section{B. Identification and Estimation}

Relevant omitted variables, measurement error, and sample selection mean that estimating Equation (1) under the assumption that $\operatorname{dur} P M_{i, 2013}$ and $e_{i}$ are independent is unlikely to yield a consistent estimate of $\alpha$. We use a two-pronged approach to overcome these challenges. First, to address omitted variables and measurement error in $\operatorname{dur} P M_{i, 2013}$, we leverage the conditional variation in $\operatorname{dur} P M_{i, 2013}$ across individuals that was induced by Clean Air Act regulations as described above. Second, to address selection based on survival, we employ a selection-correction approach.

\section{i. Instrumenting for Pollution}

As discussed in Section III, $\mathrm{PM}_{2.5}$ regulations led to lower levels of $\mathrm{PM}_{2.5}$ over

\footnotetext{
${ }^{25}$ The federal regulatory-grade monitors that we use for our analysis represent the best available information on ambient $\mathrm{PM}_{2.5}$ in the US. Appendix B provides further information on EPA's approach to validating $\mathrm{PM}_{2.5}$ measurements.
} 
2004-2013 for people living in nonattainment counties relative to people in attainment counties in the same CBSA and the same levels of $\mathrm{PM}_{2.5}$ over 2001-2003. The EPA solely relied on 2001-2003 to make its nonattainment designations. This is the essence of the quasi-experiment that we rely on to isolate conditionally exogenous variation in $\operatorname{dur} P M_{i, 2013}$. More formally, we isolate this variation using a controlfunction approach with a vector of instruments, $Z_{i}$. The five elements of $Z_{i}$ include an indicator for residing in a nonattainment county in 2004 and interactions between this indicator and $f\left(\right.$ baseP $\left.P_{i}\right)$. This set of instruments is designed to capture the between- and the within-county variation in decadal $\mathrm{PM}_{2.5}$ induced by the CAA, as discussed in Section III. Our "first-stage equation" is given by:

(2) $\operatorname{dur} P M_{i, 2013}$

$$
=\delta_{Z} Z_{i}+\delta_{X} X_{i}+\delta_{H} H_{i}+\delta_{W} W_{i}+\delta_{C} C_{i, 2013}+f\left(\text { baseP }_{i} ; \delta_{\text {basePM }}\right)+\varepsilon_{i},
$$

where the covariates other than $Z_{i}$ are the same as in Equation (1).

We assume that $\left(e_{i}, \varepsilon_{i}\right)$ is distributed jointly normal with mean zero and $\operatorname{var}\left(e_{i}\right)$ normalized to one, and is independent of the instruments, $Z_{i}$, and controls, $X_{i}, H_{i}, W_{i}, C_{i, 2013}$, and $f\left(\right.$ baseP $\left._{i}\right) .{ }^{26}$ Under this assumption, the order condition is satisfied, as the controls are exogenous and can serve as instruments for themselves, while the scalar $\operatorname{dur} P M_{i, 2013}$ is treated as endogenous and is instrumented with $Z_{i}$.

We denote the residuals from an estimation of Equation (2) via OLS as $\hat{\varepsilon}_{i}$. Following Rivers and Vuong (1988), these residuals are then added as an additional control to Equation (1), which is then treated as a standard probit model and estimated using Maximum Likelihood. ${ }^{27}$

\footnotetext{
${ }^{26}$ While assuming joint normality is standard in this class of models, Rivers and Vuong (1988) note that it is actually stronger than the sufficient condition that $e_{i}$ is normal and homoscedastic given $\varepsilon_{i}$, the instruments, $Z_{i}$, and controls, $X_{i}, H_{i}, W_{i}, C_{i, 2013}$, baseP $_{i}$. We also assume that the technical assumptions of Rivers and Vuong hold, namely that the data are i.i.d. and the parameter vector lies in the interior of a compact, convex subset of Euclidean space.

27 The Rivers and Vuong (1988) approach estimates a scaled version of the parameters in Equation (1) where the scaling
} 
The equivalence of control-function estimation in linear models and two-stage least squares (2SLS) is well established (e.g., Hausman 1978). In non-linear models like ours, the estimators are not equivalent, but the intuition of 2SLS remains applicable. This gives rise to the term Two-Stage Conditional Maximum Likelihood (2SCML) that Rivers and Vuong (1988) use to describe the approach that we rely on. Our 2SCML approach requires the standard conditions for consistency of the 2SLS estimator, i.e., that the controls are exogenous, that the instruments, $Z_{i}$, are partially correlated with $\operatorname{dur} P M_{i, 2013}$, and that the instruments, $Z_{i}$, are exogenous. ${ }^{28}$

The mean-independence assumption that guarantees exogeneity of the controls, i.e., $E\left[e_{i} \mid X_{i}, H_{i}, W_{i}, C_{i, 2013}, f\left(\right.\right.$ baseP $\left.\left._{i}\right)\right]=E\left[\varepsilon_{i} \mid X_{i}, H_{i}, W_{i}, C_{i, 2013}, f\left(\right.\right.$ baseP $\left.\left._{i}\right)\right]=0$, is equivalent to the assumption that the functional forms specified in the decomposition of $\eta$ and in Equation (2) are sufficiently flexible to capture the relationships between the controls and $\eta_{i}$ and the controls and $\operatorname{dur} P M_{i, 2013}{ }^{29}$ Three features of our research design support the credibility of this functional-form assumption. First, as discussed in Section II, our controls are extensive. Second, our model is saturated within some control vectors (e.g., integer-age-by-gender dummies and the full-factorial of baseline health conditions) and flexible in other control vectors (e.g., fourth order polynomial functions of medical spending and baseline pollution). Third, the estimated AMEs are relatively insensitive to adding additional interactions and additional flexibility in unsaturated control vectors. ${ }^{30}$

The first condition on the instruments, $Z_{i}$, (relevance) can be directly validated

factor depends on the variance of $\varepsilon_{i}$ and the covariance between $\varepsilon_{i}$ and $e_{i}$. While the unscaled coefficients can be recovered, this isn't necessary. As discussed in Wooldridge (2015), the scaled coefficients are sufficient for estimating the average structural function (Blundell and Powell 2013) and the AME of $\operatorname{durP} M_{i, 2013}$ on $\operatorname{Prob}\left(\Delta y_{i}=1\right)$.

${ }^{28}$ In a linear model, consistency requires that the controls and instruments are uncorrelated with the error. We are estimating a Probit model which requires the stronger assumptions of independence and normality.

${ }^{29}$ A necessary condition for $Z_{i}$ to be a valid instrument for $\operatorname{dur} P M_{i, 2013}$ is conditional independence, i.e., that $Z_{i}$, is independent of $\eta_{i}$, conditional on the controls. Combining this conditional independence assumption with the additional assumption that $\left(e_{i}, \varepsilon_{i}\right)$ is mean independent of the controls is then sufficient for $\left(e_{i}, \varepsilon_{i}\right)$ to be mean independent of both $Z_{i}$ and the controls.

${ }^{30}$ See, for example, the discussions in Sections IV.C, IV.D, VI.B, and Appendix J. 
with empirical testing, while the second condition (exogeneity) cannot be. A violation of the key identifying assumption of exogeneity would mean that some unobserved factor remaining in $e_{i}$ causes individuals of the same age, race, sex, and baseline health who experienced the same residential $\mathrm{PM}_{2.5}$ concentrations across 2001-2003 and lived in neighborhoods with the same socioeconomic conditions, nevertheless sorted into attainment versus nonattainment counties within the same CBSA on the basis of factors associated with different probabilities of receiving a new dementia diagnosis from 2005-2013 and yet did not have dementia prior to 2005. We follow prior studies and assume that nonattainment status is independent of measurement error in $\mathrm{PM}_{2.5}$ exposure in counties that contain air pollution monitors (Chay and Greenstone 2005, Isen et al. 2017).

We consider the earlier-in-life exposure that, as previously discussed, is an element of $e_{i}$. The EPA nonattainment designations relied only on 2001-2003 concentrations and we include a flexible (fourth-order polynomial) function of basePM$_{i}$ (created using data from 2001-2003) in our empirical models. Thus, earlier-in-life exposure would bias our estimate of $\alpha$ only in the unlikely event that earlier-in-life exposure is not independent of nonattainment status conditional on baseline pollution and other controls. We provide support for the exclusion restriction assumption in Section VI by estimating a model that includes a measure of earlier-in-life exposure. While the coefficient on earlier-in-life exposure itself is uninformative for evaluating the 2SCML assumptions, the fact that the estimates of the AMEs are invariant to its inclusion suggests that the omission of earlier exposure is not biasing our estimated effect of interest.

To conclude, like 2SLS estimators, our key identifying assumption is that the error in Equation (1) is independent of our instrument, $Z_{i}$. This is likely to hold given our extensive set of controls and the sharply defined timeframe used by the EPA to make regulatory designations. We provide support for this assumption in Section VI. 


\section{ii. Addressing Selection on Mortality}

Prior work has found that $\mathrm{PM}_{2.5}$ causes mortality among seniors in the US (Di et al. 2017, Deryugina et al. 2019). For example, Deryugina et al. uses an instrumental-variables estimator to conclude that a one-day $1 \mu \mathrm{g} / \mathrm{m}^{3}$ increase in $\mathrm{PM}_{2.5}$ causes a $0.18 \%$ increase in mortality over three days. When we estimate the specification shown in Equations (1)-(2) but with decadal mortality as the dependent variable, we find that a $1 \mu \mathrm{g} / \mathrm{m}^{3}$ increase in average PM 2.5 from 2004 through 2013 increases mortality by $2.47 \mathrm{pp}$, equivalent to $6 \%$ of the decadal mortality rate. ${ }^{31}$

These results, combined with the concern that unobserved aspects of health that determine survival may be correlated with unobserved aspects of health that determine dementia, suggest that sample selection may bias the estimates of Equations (1) and (2) when not accounting for selection on mortality. For example, suppose that unobserved aspects of health that determine survival are negatively correlated with unobserved aspects of health that determine dementia, i.e., sicker people who are more likely to die are also more likely to be diagnosed with dementia if they live. In this case, selection would bias downward the estimate of $\mathrm{PM}_{2.5}$ 's direct effect on dementia in the selected sample. ${ }^{32}$ This would mean that our estimate of $\alpha$ when ignoring selection would capture both the causal effect of $\mathrm{PM}_{2.5}$ on dementia (our object of interest) plus a compositional effect based on the set of survivors at the end of the decade. ${ }^{33}$

To address this selection issue, we obtain a selection-corrected estimate using a control-function approach (Heckman 1979, Heckman and Robb 1986). To implement this approach, we require an additional set of instruments. ${ }^{34}$ In particular, the

\footnotetext{
${ }^{31}$ Appendix Table I1 provides the estimated effects of decadal $\mathrm{PM}_{2.5}$ on mortality, i.e., an estimation of Equations (1) and (2) with mortality as the outcome in Equation (1).

${ }^{32}$ A less intuitive, but nonetheless possible, concern would be that the unobserved health determining survival was positively correlated with the unobserved health determining dementia, causing an upward bias in our estimate.

${ }^{33}$ Lee (2009) discusses this concept in detail in the context of a randomly assigned job-training program that affects whether individuals work and the level of their subsequent wages.

${ }_{34}$ In Appendix H, we show a Lee (2009) bounds approach that does not require these additional instruments, $M_{i}$, but does employ the CAA ones, $Z_{i}$, as described above.
} 
relevance and validity conditions require that the additional instruments are correlated with decadal survival but are independent of the unobserved determinants of dementia. The medical literature provides such a set of diagnoses that affect survival but do not affect dementia: prior diagnoses of a subset of non-smoking related cancers, which are found to be unrelated to dementia outcomes (Driver et al. 2012, Ganguli 2015). To form the selection-correcting control function, we begin by estimating via Maximum Likelihood a probit model of decadal survival, $S_{i}$, with the same covariates as Equation (2) plus the vector of additional instruments, $M_{i}$. We do this by specifying a latent survival propensity

(3) $S_{i}^{*}=\gamma_{Z} Z_{i}+\gamma_{X} X_{i}+\gamma_{H} H_{i}+\gamma_{W} W_{i}+\gamma_{C} C_{i, 2013}+f\left(\right.$ baseP $\left.M_{i} ; \gamma_{\text {basePM }}\right)$

$$
+\gamma_{M} M_{i}+u_{i}
$$

such that $S_{i}=1\left[S_{i}^{*}>0\right]$.

In addition to the functional-form assumptions in Equation (3), we now assume that $\left(e_{i}, \varepsilon_{i}, u_{i}\right)$ is distributed jointly normal and is independent of the instruments, $Z_{i}$, the instruments, $M_{i}$, and controls, $X_{i}, H_{i}, W_{i}, C_{i, 2013}$, and baseP $M_{i}$. We define $M_{i}$ to include indicators for baseline diagnoses of non-smoking-related cancers (leukemia, lymphoma, and cancers of the breast, prostrate, colon, rectum, and endometrium) from the CMS's Chronic Conditions Data Warehouse file. These seven cancers, which affect decadal survival, are assumed to be independent of latent features of health that affect the probability of a dementia diagnosis. ${ }^{35}$ We then use the generalized residuals of Equation (3), denoted $\hat{v}_{i}$, to define an additional control

\footnotetext{
${ }^{35}$ A potential concern is that non-smoking related cancers, while not causing dementia, could be correlated with dementia through other omitted factors. For example, a competing-risks framework could lead to a negative correlation between nonsmoking related cancers and latent health affecting dementia and lead to an upward-biased estimate of $\alpha$ in our selectioncorrection model. Such a framework would likewise suggest that estimating Equation (1) adding only the CAA-based control function would provide a downward-biased estimate. On this basis, one could interpret non-smoking related cancers as "imperfect instruments,” as defined by Nevo and Rosen (2012), and use them to partially identify $\alpha$. The estimated identification region would then simply be the interval between the two estimates.
} 
that we include in Equations (1) and (2). ${ }^{36}$

To summarize, our estimation proceeds in three steps. The first step is to estimate Equation (3) via Maximum Likelihood and create the generalized residuals, $\hat{v}_{i}$. The second step is to include $\hat{v}_{i}$ as an additional control in Equation (2), estimate Equation (2) via OLS, and recover the residuals, $\hat{\varepsilon}_{i}$. The final step is to include functions of $\hat{\varepsilon}_{i}$ and $\hat{v}_{i}$ as additional controls in Equation (1). We show this version of Equation (1) that includes the additional controls in Equation (4), which we estimate via Maximum Likelihood:

$$
\begin{aligned}
\Delta y_{i}^{*}=h\left(\operatorname{durPM} M_{i, 2013} ; \alpha_{i}\right)+\beta_{X} X_{i} & +\beta_{H} H_{i}+\beta_{W} W_{i}+\beta_{C} C_{i, 2013} \\
& +f\left(\text { basePM } M_{i} ; \beta_{\text {basePM }}\right)+\beta_{C F} C F_{i}+\tilde{e}_{i}
\end{aligned}
$$

where $\tilde{e}_{i}=e_{i}-\beta_{C F} C F_{i} . C F_{i}$ denotes the control-function vector created with the generalized residuals from the estimation of Equation (3) and the residuals from the estimation of Equation (2). We set $C F_{i}=\left[\hat{\varepsilon}_{i} \hat{\varepsilon}_{i}^{2} \hat{v}_{i} \hat{v}_{i}^{2}\right] \cdot{ }^{37}$ Because we estimate $\hat{\varepsilon}_{i}$ and $\hat{v}_{i}$ in prior stages, we bootstrap standard errors over all three regressions, clustering at the Census block-group level to allow for spatial correlation in diagnoses. ${ }^{38}$

\section{Allowing for Heterogeneity in Covariates}

In the simplest specification of the decadal model, we specify $h\left(\operatorname{dur} P M_{i, 2013} ; \alpha_{i}\right)=\alpha \operatorname{dur} P M_{i, 2013}$. However, we also estimate specifications that allow $\operatorname{dur} P M_{i, 2013}$ to enter flexibly as a fourth-order polynomial and that allow

\footnotetext{
${ }^{36}$ Generalized residuals are defined as $\hat{v}_{i}=S_{i} \lambda\left(\widehat{S^{*}}\right)-\left(1-S_{i}\right) \lambda\left(-\widehat{S^{*}}\right)$, where $\lambda(\cdot)=\phi(\cdot) / \Phi(\cdot), \phi$ and $\Phi$ are the standard normal density and CDF, respectively, and $\widehat{S^{*}}=\hat{\gamma}_{Z} Z_{i}+\hat{\gamma}_{X} X_{i}+\hat{\gamma}_{H} H_{i}+\hat{\gamma}_{W} W_{i}+\hat{\gamma}_{C} C_{i, 2013}+f\left(\right.$ basePM $\left.M_{i} ; \hat{\gamma}_{\text {basePM }}\right)+\hat{\gamma}_{M} M_{i}$. By construction, $S_{i}=1$ for all observations used in the estimation of Equations (1) and (2), therefore, for these observations, $\hat{v}_{i}=\lambda\left(\widehat{S^{*}}\right)$, simplifying to the familiar inverse Mills ratio used in Heckman (1979).

${ }^{37}$ In alternative specifications, e.g., Columns (3) and (2) of Table I, we consider a less flexible control function that only includes $\hat{\varepsilon}_{i}$ and $\hat{v}_{i}$, without their squares, as well as a version with only $\hat{\varepsilon}_{i}$, which controls for the type of endogeneity described in Section IV.B.i, but not selection on mortality.

${ }^{38}$ Our instruments vary within Census blocks across ZIP+4 codes. We alternatively cluster at the courser county level and find almost no impact on our results.
} 
for interactions between $\operatorname{dur} P M_{i, 2013}$ and the vectors $X_{i}, H_{i}, W_{i}$, and $C F_{i}$ by specifying: ${ }^{39}$

(5) $h\left(\operatorname{dur} P M_{i, 2013} ; \alpha_{i}\right)=\alpha_{1} \operatorname{dur} P M_{i, 2013}+\alpha_{2} d u r P M_{i, 2013}^{2}+\alpha_{3} \operatorname{dur} P M_{i, 2013}^{3}$

$$
\begin{aligned}
+\alpha_{4} \operatorname{dur} P M_{i, 2013}^{4}+ & \alpha_{X} X_{i} \operatorname{durP} M_{i, 2013}+\alpha_{H} H_{i} \operatorname{dur} P M_{i, 2013} \\
& +\alpha_{W} W_{i} \operatorname{dur} P M_{i, 2013}+\alpha_{\mathrm{CF}} C F_{i} \operatorname{dur} P M_{i, 2013} .
\end{aligned}
$$

In this approach, the effect of $\operatorname{dur} P M_{i, 2013}$ on the latent propensity to be newly diagnosed with dementia is allowed to vary flexibly with both the level of $\operatorname{dur} P M_{i, 2013}$, and the levels of individual characteristics, neighborhood characteristics, and control function variables. ${ }^{40,41}$

\section{Allowing PM2.5's Effect to Vary with Exposure Duration}

The contemporaneous model described in Section IV.A and IV.B is both parsimonious and comparable to the existing literature on the impacts of pollution exposure on health outcomes. However, as the treatment is measured as the average $\mathrm{PM}_{2.5}$ exposure from 2004-2013, and a dementia diagnosis can happen at any point between 2005 and 2013, there could be an aggregation bias if the data were systematically misaligned; for example, if the AME were driven by spatial correlation between dementia diagnoses in 2010 and pollution levels in 2013. The potential for misalignment due to temporal aggregation is a universal feature of research on pol-

\footnotetext{
${ }^{39}$ See Blundell and Powell $(2003,2004)$ for a discussion of estimating non-parametric, binary-response models with endogenous regressors.

${ }^{40}$ The fact that the effect of $\operatorname{dur} P M_{i, 2013}$ on new dementia diagnosis is allowed to vary with $C F_{i}=\left[\hat{\varepsilon}_{i} \hat{\varepsilon}_{i}^{2} \hat{v}_{i} \hat{v}_{i}^{2}\right]$ means that this approach nests the correlated random-coefficients model of Garen (1984) with additional assumptions. Specifically, if there exist random coefficients that satisfy the linear conditional expectation assumption of Garen (1984), they will be accounted for in our analysis. Under these assumptions, we do not find evidence of bias coming from correlated random coefficients in one's sensitivity to pollution exposure.

${ }^{41}$ Following Rivers and Vuong (1988) and Wooldridge (2015), once the control function, $C F_{i}$, is included in Equation (4), $\operatorname{dur} P M_{i, 2013}$ is independent of $\tilde{e}_{i}$ and, therefore, the non-linear functions of $d u r P M_{i, 2013}$ in Equation (5) are also independent of $\tilde{e}_{i}$. And, as we had assumed that the controls are independent of $\tilde{e}_{i}$, the interaction terms in (5) are also independent of $\tilde{e}_{i}$. Adding the 115 additional functions of the single endogenous economic variable, $\operatorname{dur} P M_{i, 2013}$, has little impact on the results as shown in Columns (4) and (5) of Table I.
} 
lution and health due to the inability to measure pollution and health instantaneously.

In this section, we extend the analysis in three ways. First, we define the outcome measure to be a new dementia diagnosis during a single year $t=$ $[2005,2013]$, thus avoiding the aggregation bias that could be introduced by misalignment of the data at the decadal level. Second, we only condition on surviving until the end of year $t$, thus incorporating the effects of $\mathrm{PM}_{2.5}$ exposure on dementia for individuals who die prior to 2013. Finally, by estimating the model separately for each year, we allow for year-specific variation in all model coefficients. This additional flexibility allows the effect of nonattainment status on $\mathrm{PM}_{2.5}$ exposure to evolve during the years after nonattainment designations were made. Moreover, it allows the effect of $\mathrm{PM}_{2.5}$ exposure on the probability of a new dementia diagnosis to evolve with the duration of exposure. In principle, such differences could arise from biological mechanisms linking $\mathrm{PM}_{2.5}$ to dementia, or from changes in the composition of people surviving from one year to the next.

Equations (6) and (7) describe the analogues to Equations (4) and (5), respectively, where $\Delta y_{i, t}^{*}$ now denotes the latent propensity to become newly diagnosed with dementia during year $t$. We estimate Equation (6) separately for each year 2005 to 2013 via Maximum Likelihood.

$$
\begin{aligned}
\Delta y_{i, t}^{*}=h\left(\operatorname{durPM}_{i, t} ; \alpha_{i, t}\right)+\beta_{X, t} X_{i} & +\beta_{H, t} H_{i}+\beta_{W, t} W_{i}+\beta_{C, t} C_{i, t} \\
& +f\left(\text { basePM }_{i} ; \beta_{\text {basePM }, t}\right)+\beta_{C F, t} C F_{i, t}+\tilde{e}_{i, t}
\end{aligned}
$$

$$
\text { where } \tilde{e}_{i, t}=e_{i, t}-\beta_{C F, t} C F_{i, t} \text {, }
$$

$$
\begin{array}{r}
h\left(\operatorname{dur} P M_{i, t} ; \alpha_{i, t}\right)=\alpha_{1, t} \operatorname{dur} P M_{i, t}+\alpha_{2, t} \operatorname{dur} P M_{i, t}^{2}+\alpha_{3, t} \operatorname{dur} P M_{i, t}^{3} \\
+\alpha_{4, t} \operatorname{dur} P M_{i, t}^{4}+\alpha_{X . t} X_{i} \operatorname{dur} P M_{i, t}+\alpha_{H, t} H_{i} d u r P M_{i, t} \\
+\alpha_{W, t} W_{i} d u r P M_{i, t}+\alpha_{C F, t} C F_{i, t} \operatorname{dur} P M_{i, t}
\end{array}
$$


and $C F_{i, t}$ denotes a control-function vector, $\left[\hat{\varepsilon}_{i, t} \hat{\varepsilon}_{i, t}^{2} \hat{v}_{i, t} \hat{v}_{i, t}^{2}\right]$, created with the generalized residuals from the estimation of Equation (8) (the analogue to Equation (3)) and the residuals from the estimation of Equation (9) (the analogue to Equation (2)):

$$
\begin{aligned}
& S_{i, t}=1\left(\gamma_{Z, t} Z_{i}+\gamma_{X, t} X_{i}+\gamma_{H, t} H_{i}+\gamma_{W, t} W_{i}+\gamma_{C, t} C_{i, t}\right. \\
&+\left.f\left(\text { baseP }_{i} ; \gamma_{\text {basePM }, t}\right)+\gamma_{M, t} M_{i}+u_{i, t}>0\right),
\end{aligned}
$$

$$
\begin{aligned}
\operatorname{durP} M_{i, t}=\delta_{Z, t} Z_{i}+\delta_{X, t} X_{i}+\delta_{H, t} H_{i} & +\delta_{W, t} W_{i}+\delta_{C, t} C_{i, t} \\
& +f\left(\text { basePM }_{i} ; \delta_{\text {basePM }, t}\right)+\hat{v}_{t, i}+\varepsilon_{t, i} .
\end{aligned}
$$

We begin by estimating Equation (8) via Maximum Likelihood on the full sample of individuals. The survival outcome, $S_{i, t}$, now indicates whether individual $i$ is still alive through the end of year $t$ and has not previously received a dementia diagnosis. We then estimate the year-t-specific pollution Equation (9) via OLS. This equation includes the generalized residuals from the survival function, $\hat{v}_{i, t}$. Equations (9) and (6) are estimated using the subset of people who are still alive through the end of year $t$ and had not been diagnosed with dementia prior to year $t$.

We then use the year-t-specific parameter vector, $\hat{\alpha}_{t}$, to calculate $A M E_{t}$, the average effect of a marginal increase in $\mathrm{PM}_{2.5}$ exposure from 2004 through year $t$ on the probability of receiving a new dementia diagnosis during year $t$. We additionally calculate the cumulative effect of $\mathrm{PM}_{2.5}$ exposure from 2004 through year $t$ on new dementia diagnoses during that period according to,

$$
\text { cumulative } A M E_{t}=\sum_{s=2005}^{t}\left(\frac{p o p_{s}}{\text { pop }_{2005}}\right) A M E_{s}
$$

by summing the year-specific average marginal effects, after weighting them by their corresponding shares of the original population to account for attrition due to 
dementia and death. ${ }^{42}$ Finally, we bootstrap standard errors on cumulativeAME by repeating estimation of Equations (6)-(10) after resampling from the original population one thousand times with replacement and clustering at the Census blockgroup level.

\section{Results}

\section{A. $P M_{2.5}$ Regulations Created Conditional Differences in Subsequent $P M_{2.5}$}

The identifying variation for our estimator comes from the fact that the EPA's nonattainment designations created quasi-random differences in $\operatorname{dur} P M_{i, t}$ for $t=$ [2005,2013], conditional on baseP $M_{i}$ and the additional controls in Equations (2) and (9). Figure IV shows this identifying variation for the year 2013. Specifically, it uses the coefficients on the instruments from the year-2013 version of Equation (9) to plot the estimated partial effect of nonattainment on $\operatorname{dur} P M_{i, 2013}$ across levels of $\operatorname{basePM}_{i}$. Similar figures plotting the estimated partial effect for $t=$ $[2005,2012]$ versions of Equation (9), as well as the decadal version in Equation (2), are shown in Appendix I1. Intuitively, the partial effects are negative, showing that nonattainment status reduced pollution. In addition, as permitted (but not determined) by our construction of $Z_{i}$, the partial effects vary with baseline $\mathrm{PM}_{2.5}$. This yields within-county identifying variation in $\operatorname{dur} P M_{i, t}$ in all years. ${ }^{43}$ The firststage partial $\mathrm{R}^{2}$ of the identifying instruments is 0.047 and the $\mathrm{F}$ statistic is 489 for the regression underlying Figure IV, suggesting that any finite sample bias is negligible. The size of the F statistic reflects the number of observations (approximately 1 million) and number of Census block group clusters (approximately 140 thousand).

\footnotetext{
${ }^{42}$ For example, we multiply the estimated AME in 2009 by 0.65 because $65 \%$ of the original year-2005 sample survives to the end of 2009. This adjusts for the progressive decline in sample size due to dementia and mortality.

${ }^{43}$ While nonattainment status caused reductions in $\operatorname{dur} P M_{i, t}$ at all levels of basePM $M_{i}$, these reductions are larger at lower baseline levels.
} 
Figure IV: Estimated Partial EfFEct of NonAtTainMENT ON PM 2.5 ExPOSURE 2004-2013, By BASELINE CONCENTRATIONS 2001-2003

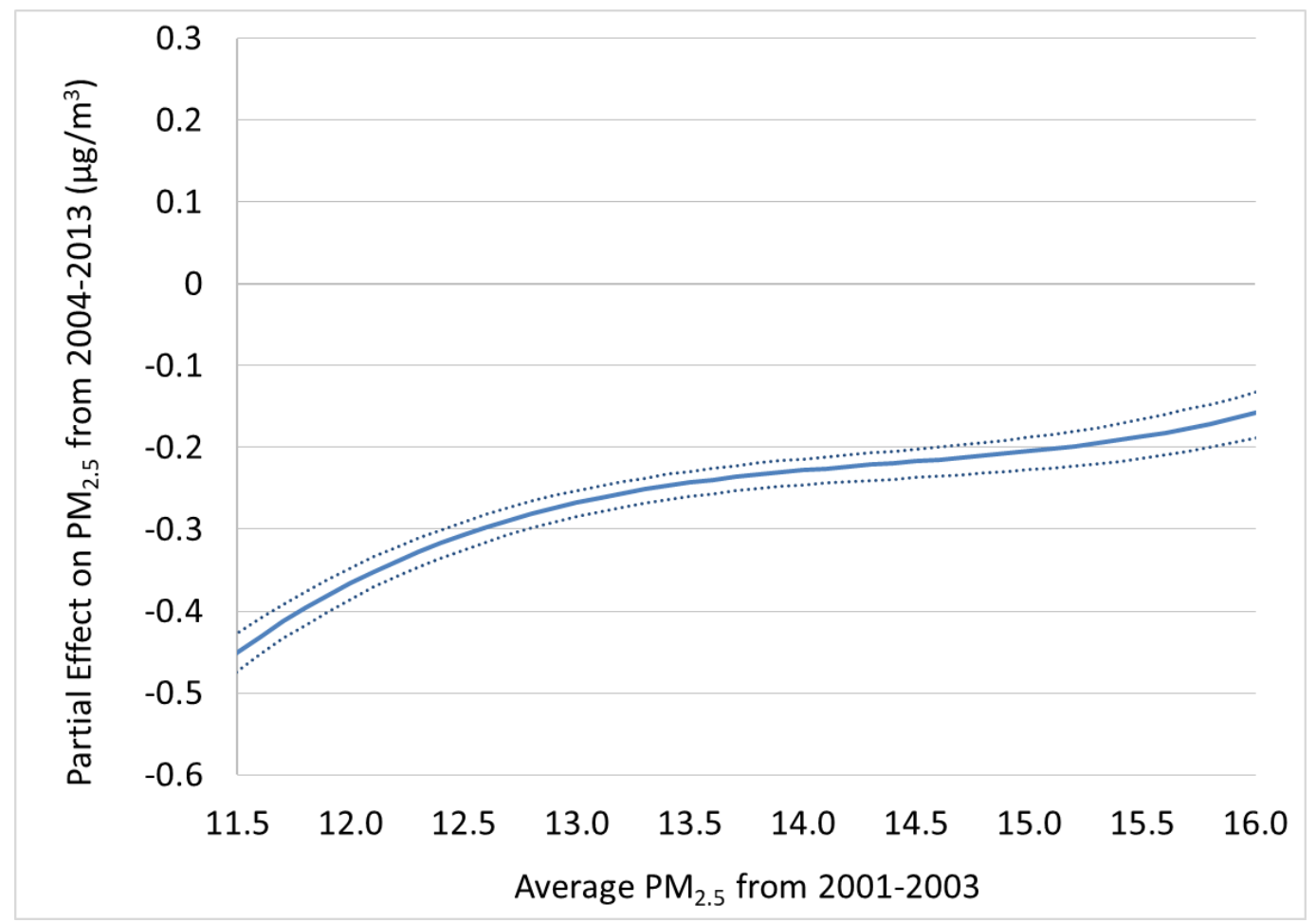

Note: The figure shows the average effect of the county-level nonattainment designation on the average individual-level conditional change in $\mathrm{PM}_{2.5}$ concentrations over the period 2004-2013. The zero line represents individuals living in attainment counties at the same baseline $\mathrm{PM}_{2.5}$ concentration and holding all else in Equation (9) constant. The dotted lines denote 95\% confidence bands constructed from 1,000 bootstrap replications, with clustering at the Census block group.

\section{B. The Effect of $P M_{2.5}$ on Dementia}

We find that a $1 \mu \mathrm{g} / \mathrm{m}^{3}$ increase in average $\mathrm{PM}_{2.5}$ concentrations starting in 2004 increases the probability of receiving a new dementia diagnosis before the end of 2013 by an average of 2.15 percentage points (pp). To illustrate the importance of various aspects of our identification strategy, we present the AME of cumulative $\mathrm{PM}_{2.5}$ exposure over the decade on new dementia diagnoses from six specifications described in Section IV.

The first column of Table I begins with a simple, associative model of decadal $\mathrm{PM}_{2.5}$ and dementia diagnosis over the decade. The next four columns retain the 
contemporaneous, decadal specification and incrementally address potential confounders that may underlie this association, as previously discussed. The final column presents our preferred specification that aggregates year-by-year marginal effects over the decade while addressing all of the potential confounders described in Section IV. In all cases, the AMEs are scaled to represent percentage point (pp) changes in the probability of receiving a new dementia diagnosis by the end of 2013.

Table I-Average Marginal Effect of Cumulative PM2.5 ON the ProbabilITY OF A NEW DEMENTIA DIAGNOSIS

\begin{tabular}{|c|c|c|c|c|c|c|}
\hline & (1) & $(2)$ & (3) & (4) & (5) & (6) \\
\hline$\left(1 \mu \mathrm{g} / \mathrm{m}^{3}\right.$ increase in decadal $\left.\mathrm{PM}_{2.5}\right)$ & $\begin{array}{c}0.629 * * * \\
(0.058)\end{array}$ & $\begin{array}{c}0.124 \\
(0.105)\end{array}$ & $\begin{array}{c}1.545^{* * *} \\
(0.536)\end{array}$ & $\begin{array}{c}2.283^{* * *} \\
(0.565)\end{array}$ & $\begin{array}{c}2.384^{* * *} \\
(0.568)\end{array}$ & $\begin{array}{c}2.151^{* * *} \\
(0.846)\end{array}$ \\
\hline individual \& neighborhood covariates & & $x$ & $x$ & $x$ & $x$ & $x$ \\
\hline $\mathrm{PM}_{2.5}$ control function & & & $x$ & $x$ & $x$ & $x$ \\
\hline survival control function & & & & $\mathrm{x}$ & $x$ & $x$ \\
\hline polynomial functions and interactions & & & & & $x$ & $x$ \\
\hline heterogeneity by exposure duration & & & & & & $x$ \\
\hline F-statistic on $\mathrm{PM}_{2.5}$ instruments & & & 496 & 498 & 498 & 165 to 489 \\
\hline $\begin{array}{l}\text { number of individuals: } \\
\text { dementia function }\end{array}$ & $1,179,094$ & $1,179,094$ & $1,179,094$ & $1,179,094$ & $1,179,094$ & $\begin{array}{l}989,751 \text { to } \\
2,293,270\end{array}$ \\
\hline $\begin{array}{l}\text { Chi-square statistic on survival } \\
\text { instruments }\end{array}$ & & & & 3,813 & 3,813 & $\begin{array}{l}1,166 \text { to } \\
2,274\end{array}$ \\
\hline $\begin{array}{l}\text { number of individuals: } \\
\text { survival function }\end{array}$ & & & & $2,439,904$ & $2,439,904$ & $2,439,904$ \\
\hline
\end{tabular}

Note: The outcome is scaled to equal 100 if an individual was diagnosed with dementia and 0 otherwise. By 2013, 20\% of the individuals in our sample who were alive in that year had been diagnosed with dementia. In Column (1) the covariates are $\mathrm{PM}_{2.5}$ and CBSA dummies. Column (2) adds covariates for baseline health in 2004, individual demographics, demographics for the individual's Census block group, and pre-regulatory (2001-2003) $\mathrm{PM}_{2.5}$ levels at their residence. Column (3) adds a control function for $\mathrm{PM}_{2.5}$. Column (4) adds a control function for survival. Column (5) adds additional polynomial functions of covariates. Column (6) reports a cumulative decadal AME that aggregates year-specific AMEs, along with ranges for the year-specific F-statistics, Chi-square statistics, and sample sizes. Year-specific estimates are reported in Table I5. Asterisks indicate statistical significance at the $10 \%(*), 5 \%(* *)$, and $1 \%(* * *)$ levels using robust standard errors clustered at the block group. Standard errors in Columns (3) through (6) are bootstrapped using 1,000 repetitions.

Column (1) in Table I shows the result from a simple associative model of decadal $\mathrm{PM}_{2.5}$ and dementia diagnosis over the decade. The only covariates are CBSA 
dummies. The result indicates that a $1 \mu \mathrm{g} / \mathrm{m}^{3}$ increase in average decadal $\mathrm{PM}_{2.5}$ is associated with a 0.63 pp higher probability of receiving a dementia diagnosis between 2005 and 2013.

Column (2) then additionally includes the observed characteristics represented by $X_{i}, H_{i}, W_{i}$ and $f\left(\right.$ baseP $\left._{i}\right)$ in Equation (1). Adding these covariates reduces the conditional association between measured decadal $\mathrm{PM}_{2.5}$ and dementia over the decade to $0.12 \mathrm{pp}$. Thus, most of the within-CBSA association between measured $\mathrm{PM}_{2.5}$ and new dementia diagnoses can be explained by people with observably higher baseline risks of dementia living in more polluted neighborhoods. Notably, 99\% of the decline that occurs as we move from Column (1) to Column (2) can be explained by the inclusion of $X_{i}, H_{i}$, and $W_{i}$. When all of these covariates are included, adding $f\left(\right.$ basePM$_{i}$ ) only reduces the AME for $\mathrm{PM}_{2.5}$ exposure from 20042013 by 1\%. This shows that our extensive measures of individual demographics, baseline health, and neighborhood characteristics explain almost all of the heterogeneity that contributes to any association between neighborhood $\mathrm{PM}_{2.5}$ in 20012003 and new dementia diagnoses.

Column (3) adds the $\mathrm{PM}_{2.5}$ control function to address measurement error in pollution exposure, or any residual differences driven by sorting. The resulting order-of-magnitude increase in the AME relative to Column (2) is unsurprising. First, our extensive set of geographic controls could potentially exacerbate the effect of any measurement error in pollution. Second, while the bias introduced by measurement error is ambiguous in general, prior studies have consistently found that instrumenting for (shorter-term) measures of air pollution exposure results in orderof-magnitude increases in estimates for its effects on other morbidities and mortality among older adults (see, for example, Schlenker and Walker 2016, Deschênes, Greenstone, and Shapiro 2017, and Deryugina et al. 2019). ${ }^{44}$

\footnotetext{
${ }^{44}$ These studies find that instrumenting for air pollution increases their estimates for its effects on morbidity and mortality by factors ranging from 6 to 20. The twelve-fold increase in our Table I estimates sits near the middle of this range.
} 
Column (4) adds the survival control function to address selection on mortality. ${ }^{45}$ Controlling for selection on survival increases the AME to 2.28 pp, a $48 \%$ increase relative to Column (3). This increase is consistent with classic selection bias caused by positively correlated latent health: individuals who were more likely to die were also more likely to develop dementia. ${ }^{46}$

Column (5) shows the AME from our specification shown in Equations (4)-(5) that allows for additional parametric flexibility in the covariates. ${ }^{47}$ This only increases the AME to $2.38 \mathrm{pp}$, which is about a $4 \%$ increase relative to Column (4) ${ }^{48}$

The final AME shown in Column (6) shows the cumulative AME at the end of the decade as shown in Equations (6) through (10). This model differs from the model underlying the AME in Column (5) in three potentially important ways. First, it limits aggregation bias that could be introduced by the misalignment of the data at the decadal level. Second, it incorporates the effects of $\mathrm{PM}_{2.5}$ exposure on dementia for people who die during the decade, almost doubling the number of observations used in estimation. Finally, it allows the effect of $\mathrm{PM}_{2.5}$ exposure on the probability of a new dementia diagnosis to evolve with the duration of exposure, as shown in Equation (6).

This cumulative AME indicates that a $1 \mu \mathrm{g} / \mathrm{m}^{3}$ increase in average $\mathrm{PM}_{2.5}$ increases the cumulative probability of a new dementia diagnosis by the end of 2013 by $2.15 \mathrm{pp}$. Comparing this cumulative AME against the results from the more parsimonious model in Column (5) indicates that the three notable differences between the two approaches yields only a small difference in the economic magnitude of their estimated effects ( $0.23 \mathrm{pp})$.

\footnotetext{
45 The average marginal effects of the survival instruments are reported in Appendix Table I2.

${ }^{46}$ We build on this result and develop a partial-identification approach to exploring the role of selection on survival in Appendix H.

${ }^{47}$ Appendix Table I3 reports the full results from this specification. Appendix Table 44 compares the AME for PM 2.5 from this specification to the AMEs that we estimate for other dementia risk factors that were included as covariates in the model. Note that we do not consider the coefficients on risk factors other than decadal $\mathrm{PM}_{2.5}$ to reflect a causal relationship.

${ }^{48}$ When we run this specification using a linear-probability model, we find an AME of 2.16 pp that is statistically significant the $1 \%$ level.
} 
To provide context for the AME of 2.15pp, a $1 \mu \mathrm{g} / \mathrm{m}^{3}$ change is equivalent to 9.1\% of the average person's exposure between 2004 and 2013 and 59\% of a standard deviation. A 2.15 pp change in the dementia diagnosis rate is a $11 \%$ increase relative to the diagnosis rate among people in our sample who survive to the end of 2013. To provide an age-based comparison to this statistic, the dementia diagnosis rate in 2013 was 2.2 pp higher among 80-year-old women compared with 79-yearold women (Figure I). ${ }^{49}$

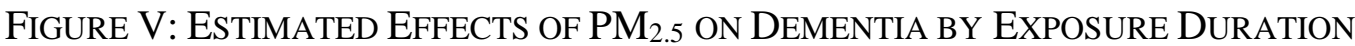

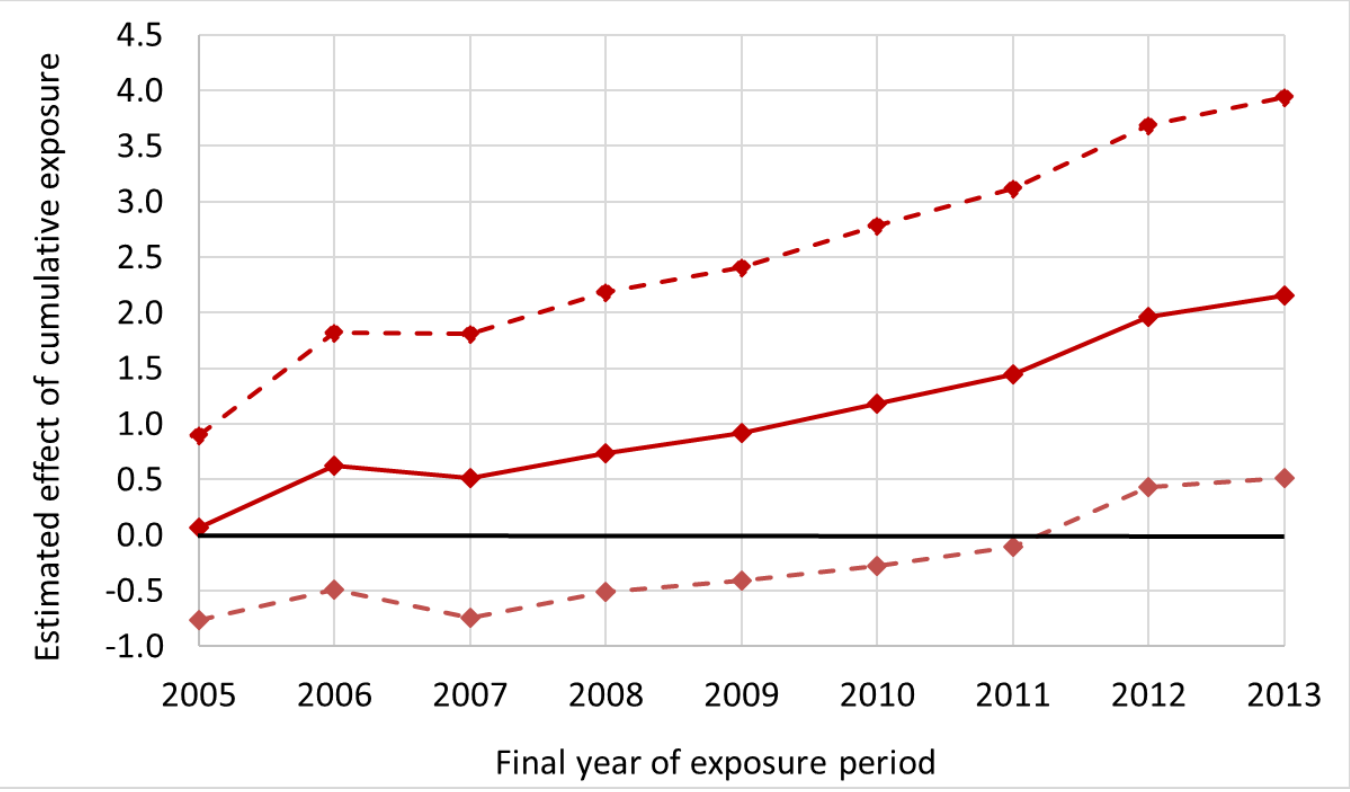

Figure V shows how our estimates of the cumulative AME evolve over time, along with 95\% bootstrapped confidence intervals. The underlying year-specific

${ }^{49}$ To compare these results to earlier medical literature, Gatz et al. (1997) finds that approximately $74 \%$ of Alzheimer’s disease cases are heritable using twin pairs. We impose the additive separability assumption underlying that statistic and perform a back-of-the-envelope calculation to see how much variation in new dementia diagnoses could be explained by decadal $\mathrm{PM}_{2.5}$ exposures after age 65 in our sample. Specifically, we use a linearized and additively separable version of our decadal model to calculate $\left(\left(\mathrm{AME}^{2} \operatorname{Var}(\operatorname{durPM})\right) /(\operatorname{Var}(\Delta \mathrm{y})) \approx 1 \%\right.$, where $\mathrm{AME}=0.0238$ (this number is multiplied by 100 when discussed in the text), $\operatorname{Var}(\operatorname{dur} P M)=2.8812$, and $\operatorname{Var}(\Delta y)=0.1572$. We thank an anonymous referee for this suggestion. 
AMEs are presented in Appendix Table I5. While the year-specific AMEs are imprecisely estimated, the AME for 2005 is close to zero and, starting in 2008, the year-specific AMEs are positive in each year, which is reflected in the increasing cumulative AME shown in Figure V. In addition, the year-specific AMEs are generally increasing in the duration of exposure. When we weight the year-specific AMEs by the surviving share of the baseline population to account for attrition, as shown in Equation (10), the resulting weighted year-specific AMEs become similar in magnitude. This similarity is reflected in the approximately-linear trend in cumulative AME point estimates shown in Figure V, although visual inspection of the confidence intervals suggests that we lack the statistical power to rule out a nonlinear function.

\section{Heterogeneity in Effects}

The results shown in Column (6) of Table 1 average over considerable heterogeneity in the marginal effects of $\mathrm{PM}_{2.5}$ exposure. Interestingly, the cumulative AME's tend to be larger among individuals who experienced lower levels of $\mathrm{PM}_{2.5}$. To illustrate this, we divide individuals into terciles by their baseline residential exposures during 2001-2003. Individuals in the top tercile of baseline exposure (above $14.2 \mu \mathrm{g} / \mathrm{m}^{3}$ ) experienced a cumulative AME of $1.91 \mathrm{pp}$. In comparison, individuals in the middle tercile (whose baseline exposures were between 12.4 and $14.2 \mu \mathrm{g} / \mathrm{m}^{3}$ ) experienced an AME of $2.10 \mathrm{pp}$. Individuals with baseline exposures below $12.4 \mu \mathrm{g} / \mathrm{m}^{3}$ experienced an AME of $2.45 \mathrm{pp}$. For those in the top, middle and bottom terciles who survived through 2013, average exposures from 2004-2013 were 12.46, 11.14 and $9.24 \mu \mathrm{g} / \mathrm{m}^{3}$, respectively. These results highlight that the effects of $\mathrm{PM}_{2.5}$ on dementia persist well below the current US regulatory threshold of $12 \mu \mathrm{g} / \mathrm{m}^{3}$ of annual average concentrations.

The estimates also show heterogeneity across individual characteristics. For example, the cumulative AME is larger for individuals whose exposures we observe 
at older ages (e.g., 1.13 pp for people born in 1938 for whom we observe quasirandom variation in exposure from age 66 up to age 75, compared with 2.34 pp for people born in 1928 for whom we observe variation in exposure from age 76 up to age 85). Conditional on age at exposure, the AME is higher for women compared with men (e.g., 2.57 pp for women born in 1928 compared with 2.03 pp for men born in 1928). Conditional on age and sex, the AME is higher for individuals with more clinical risk factors for dementia at the start of the decade (e.g., 2.24 pp for women born in 1928 with no baseline clinical risk factors compared with 2.61 pp for women born in 1928 who had been diagnosed with ischemic heart disease and hypertension at baseline). Finally, when we condition on $\mathrm{PM}_{2.5}$ exposure, the AME is higher among individuals denoted by CMS as "Black or African-American” compared with "non-Hispanic White” (e.g., 0.21 pp higher among women born in 1928 whose baseline exposure to $\mathrm{PM}_{2.5}$ was within a one-unit window of the sample median of $\left.13.4 \mu \mathrm{g} / \mathrm{m}^{3}\right){ }^{50}$

\section{Main Validation Tests and Additional Sensitivity Analysis}

\section{A. Main Validation Tests}

Table II presents three validation tests of our estimator. First, we assess the assumption that our nonattainment instrument is independent of earlier-in-life measures of $\mathrm{PM}_{2.5}$, conditional on baseline $\mathrm{PM}_{2.5}$ exposure and the other covariates. Specifically, we examine whether the AME shown in Table I, Column (6) changes when we add measures of earlier-in-life exposures, specifically average annual $\mathrm{PM}_{2.5}$ in 1999 and 2000. ${ }^{51}$ These are the first two years that the US EPA had a national network of $\mathrm{PM}_{2.5}$ monitors and the first two years that researchers can obtain administrative data describing the Medicare population. Thus, this validation

\footnotetext{
${ }^{50}$ Average decadal $\mathrm{PM}_{2.5}$ exposures in our estimation sample were 6\% higher for Black or African-American individuals compared with non-Hispanic White individuals who survived through 2013.

${ }^{51}$ In the years of 1999 and 2000, 86\% of our balanced panel of monitors were in operation.
} 
test exhausts the available data. For the $23 \%$ of our sample that were under age 65 in those years and not yet enrolled in Medicare, we assign 1999 and 2000 PM$_{2.5}$ exposures based on the location where we first observe these individuals living upon enrolling in Medicare. While this assignment is imperfect, low short-term migration rates among this age group limit the scope for error. For example, the year 2000 Census of Population reports that $77 \%$ of people aged 65-69 lived in the same residence as they did five years ago.

\section{TABLE II-VALIDATION TESTS}

\begin{tabular}{|c|c|c|c|c|}
\hline & (1) & (2) & (3) & (4) \\
\hline $\begin{array}{l}\text { Probit model average marginal effect } \\
\left(1 \mu \mathrm{g} / \mathrm{m}^{3} \text { increase in decadal } \mathrm{PM}_{2.5}\right)\end{array}$ & $\begin{array}{c}2.151^{* * *} \\
(0.846)\end{array}$ & $\begin{array}{c}2.246 * * * \\
(0.929)\end{array}$ & $\begin{array}{l}1.754^{* *} \\
(0.704)\end{array}$ & $\begin{array}{l}-0.167 \\
(0.283)\end{array}$ \\
\hline \multicolumn{5}{|l|}{ modification to main specification } \\
\hline control for $\mathrm{PM}_{2.5}$ in 1999 and 2000 & & $\mathrm{x}$ & & \\
\hline control for other regulated air pollutants & & & $x$ & \\
\hline placebo outcome = dementia in 2004 & & & & $\mathrm{x}$ \\
\hline F-statistic on $\mathrm{PM}_{2.5}$ instruments & 165 to 489 & 147 to 492 & 146 to 350 & 620 \\
\hline number of individuals: dementia function & 989,751 to $2,293,270$ & 989,751 to $2,293,270$ & 989,751 to $2,293,270$ & $2,734,032$ \\
\hline Chi-square statistic on survival instruments & 1,166 to 2,274 & 1,166 to 2,274 & 1,168 to 2,277 & \\
\hline number of individuals: survival function & $2,439,904$ & $2,439,904$ & $2,439,904$ & \\
\hline
\end{tabular}

Note: The first column repeats our main result from Table I, Column (6) for comparison. The next three columns report results from alternative specifications that are designed to test the identifying assumptions that underlie our main specification. Asterisks indicate statistical significance at the $10 \%(*), 5 \%(* *)$, and $1 \%(* * *)$ levels based on robust standard errors clustered at the Census block group. See the note to Table I and main text for further details.

If the exclusion restrictions on $Z_{i}$ are valid, then adding controls for earlier-inlife $\mathrm{PM}_{2.5}$ should not change the estimated AME of cumulative exposure over the decade. Column (2) shows that this augmented specification yields an AME of 2.25 pp. This is similar to the AME of 2.15 pp from our main specification (repeated in Column (1) for convenience). This similarity reinforces the validity of the instrument and is consistent with the EPA's nonattainment designation criteria, which relied solely on $\mathrm{PM}_{2.5}$ concentrations in 2001-2003.

The specification in Column (3) tests whether our results are confounded by the model's omission of air pollutants that may be co-generated with $\mathrm{PM}_{2.5}$. Specifi- 
cally, we add measures of exposure to $\mathrm{PM}_{10}$, ozone, nitrogen dioxide, sulfur dioxide, and carbon monoxide. Each measure is constructed following the same procedures that we used to construct measures of cumulative $\mathrm{PM}_{2.5}$. When we control for these ancillary pollutants, the cumulative AME for $\mathrm{PM}_{2.5}$ remains large and precisely estimated.

Additionally, we test for sorting based on unobserved risk factors, such as genetics, that may contribute to dementia and be correlated with $\mathrm{PM}_{2.5}$. In principle, sorting on unobserved risk factors could bias the estimator if, prior to our study period, people at a lower unobserved risk for dementia sorted themselves into neighborhoods that were more or less likely to be designated as nonattainment in the future, even conditional on baseline neighborhood $\mathrm{PM}_{2.5}$ and the other controls. While we cannot directly test this sorting hypothesis in our main estimation sample, we can test it indirectly by extending the sample to include the people who were excluded because they were diagnosed with dementia prior to 2005. In other words, if individuals sorted themselves into future nonattainment areas based on unobserved dementia risk then we would expect to see a conditional relationship between dementia rates in 2004 and $\mathrm{PM}_{2.5}$ exposure over the subsequent decade. ${ }^{52}$ We test this hypothesis using a placebo specification that replaces the outcome in Equation (4) with an indicator for a dementia diagnosis in 2004. Including everyone alive in 2004, with or without dementia, increases our sample size to 2.7 million. Column (4) shows that the estimated AME is negative, close to zero, and estimated relatively precisely. This provides supporting evidence that the exclusion restriction is unlikely to be violated by initial differences in unobserved dementia risk, including unobserved genetic factors.

\section{B. Additional Sensitivity Analysis}

\footnotetext{
52 Intuitively, under the hypothesis that people sorted into future nonattainment areas based on unobserved dementia risk, some people would have been diagnosed with dementia prior to 2005 and been dropped from our estimation sample, while others would have been diagnosed after 2005 and been included in our estimation sample.
} 
The effect of $\mathrm{PM}_{2.5}$ on dementia persists when we use (1) different measures of dementia such as the use of prescription drugs for the symptoms of Alzheimer's disease rather than claims-based diagnosis codes; (2) different samples that include people who select into managed care plans known as Medicare Advantage; (3) monitor-level attainment indicators rather than county-level indicators; (4) different approaches to measuring $\mathrm{PM}_{2.5}$ exposure including expanding the set of monitors to include those not present for the entire study period, (5) a limited sample of individuals who live close to a monitor, and (6) controls for baseline pollution exposure that are even more flexible than the fourth-order polynomial function described above. We present and discuss these results in Appendix J.

Finally, we estimate models for placebo health outcomes. We examine five chronic conditions that are not known or suspected to be caused by air pollution but share similarities with dementia in terms of how they affect the body, how they are diagnosed, and how diagnosis rates are correlated with age, race, and gender. These are glaucoma, fibromyalgia, breast cancer, prostate cancer, and peripheral vascular disease. ${ }^{53}$ Appendix Table J5 shows that we fail to reject the null hypothesis of zero effect at the $10 \%$ significance level for each of these placebos. We elaborate on these models and results in the appendix.

Our criteria for selecting placebos excluded illnesses that have previously been linked to air pollution. When we instead ignore these criteria and repeat estimation for each of the 15 most common chronic conditions among the Medicare population including those linked to pollution exposure, we find positive effects of $\mathrm{PM}_{2.5}$ at the $5 \%$ level for two diseases besides dementia: chronic obstructive pulmonary disease $(\mathrm{COPD})[\mathrm{AME}=1.79, \mathrm{p}=0.002]$ and chronic kidney disease $[\mathrm{AME}=1.15$,

\footnotetext{
${ }^{53}$ Glaucoma is a progressive disorder with nerve degeneration that is strongly associated with age; fibromyalgia affects mood and behavior and can be difficult to diagnose; breast cancer and prostate cancer can be slow to progress and have genderspecific diagnosis rates; and peripheral vascular disease is associated with reduced blood circulation.
} 
$\mathrm{p}=0.038] .{ }^{54}$ These results could be interpreted as "reverse placebo tests" in the sense that positive findings may be expected based on prior cohort studies that found that long-term exposure to $\mathrm{PM}_{2.5}$ is associated with these diseases (e.g., Guo et al. 2018).

\section{Conclusion}

Dementia's global social costs continue to grow with the aging populations of many countries, causing the World Health Organization to label it a "public health priority" and the US Centers for Disease Control to describe it as a "public health crisis.” Because no medical preventions or cures exist, policy discussions have focused on investment in research and health infrastructure and modifying behaviors related to smoking, diet, and exercise. Our findings reveal that air quality regulations provide another lever to policy makers to reduce the prevalence of dementia.

Beyond these policy implications, our results provide guidance for additional research on the causes and consequences of dementia. Our study establishes a causal link between long-term, later-in-life exposure to $\mathrm{PM}_{2.5}$ and dementia, yet the precise mechanisms and causal pathways remain unknown. Research can investigate how the presence of small particulates in the brain alters cognitive function and relates to Alzheimer's disease specifically, and whether the effects differ across chemical composition, genotypes, comorbidities, stages of life, or other factors. Likewise our results can help guide efforts to study the broader link between air pollution, cognitive decline and financial decision making. Such insights can shed light on the economic costs of impaired cognition as well as the value of various approaches to mitigate these costs, whether through the provision of long-term care

\footnotetext{
${ }^{54}$ According to the Centers for Medicare and Medicaid Services (2012) the top 15 conditions ranked from most prevalent to least prevalent are high blood pressure, high cholesterol, ischemic heart disease, arthritis, diabetes, heart failure, chronic kidney disease, depression, COPD, Alzheimer's disease, atrial fibrillation, cancer, osteoporosis, asthma, and stroke.
} 
and long-term care insurance, support for family caregivers, financial decision support, and medical technologies.

\section{REFERENCES}

Archsmith, James, Anthony Heyes and Soodeh Saberian. 2018. "Air Quality and Error Quantity: Pollution and Performance in a High-skilled, Quality-focused Occupation". Journal of the Association of Environmental and Resource Economists, 5(4): 827-863.

Alemany, Silvia, Marta Crous-Bou, Natalia Vilor-Tejedor et al. 2021. “ Associations between air pollution and biomarkers of Alzheimer's disease in cognitively unimpaired individuals.” Environment International. 157: 106864.

Alzheimer’s Association. 2019. "2019 Alzheimer's Disease Facts and Figures.” https://www.alz.org/media/Documents/alzheimers-facts-and-figures-2019r.pdf.

Angrist, Joshua, and Jörn-Steffen Pischke. 2009. Mostly Harmless Econometrics: An Empiricist's Companion. Princeton University Press.

Auffhammer, Maximilian, Antonio M. Bento and Scott E. Lowe. 2009. "Measuring the Effects of the Clean Air Act Amendments on Ambient PM10 Concentrations: The Critical Importance of a Spatially Disaggregated Analysis.” Journal of Environmental Economics and Management, 58: 15-26.

Bento, Antonio, Matthew Freedman and Corey Lang. 2015. "Who Benefits from Environmental Regulation? Evidence from the Clean Air Act Amendments." Review of Economics and Statistics, 97(3): 610-622.

Block M.L., et al. 2012. "The Outdoor Air Pollution and Brain Health Workshop.” NeuroToxicology, 33: 972-984.

Blundell, Richard and James L. Powell. 2003. "Endogeneity in Nonparametric and Semiparametric Regression Models.” Econometric Society Monographs, 36: 312-357.

Blundell, Richard and James L. Powell. 2004. "Endogeneity in Semiparametric Binary Response Models.” Review of Economic Studies. 71: 655-679.

Carey I.M. et al. 2018. "Are Noise and Air Pollution Related to the Incidence of Dementia? A Cohort Study in London, England.” BMJ Open 2018;8:e022404. doi: 10.1136/bmjopen-2018-022404

Cacciottolo, M, X Wang, I Driscoll et al. 2017. "Particulate Air Pollutants, APOE Alleles and Their Contributions to Cognitive Impairment in Older Women And to Amyloidogenesis in Experimental Models.” Translational Psychiatry, 7: $1-8$. 
Chay, Kenneth Y. and Michael Greenstone. 2005. "Does Air Quality Matter? Evidence from the Housing Market.” J. of Political Economy, 113(2): 376-424.

Chang, Tom, Joshua Graff-Zivin, Tal Gross and Matthew Neidell. 2016. "Particulate Pollution and the Productivity of Pear Packers.” American Economic Journal: Economic Policy, 8(3): 141-69.

Deaton, Angus S. and Christina H. Paxson. 1998. “Aging and Inequality in Income and Health.” American Economic Review: Papers and Proceedings. 88 (2): 248-253.

Deryugina, Tatyana, Garth Heutel, Nolan H. Miller and David Molitor. 2019. "The Mortality and Medical Costs of Air Pollution: Evidence from Changes in Wind Direction.” American Economic Review, 109(12): 4178-4219.

Driver, Jane A.et al. 2012. "Inverse Association Between Cancer and Alzheimer's Disease: Results from the Framingham Heart Study.” BMJ, 344:e1442.

Ebenstein, Avraham, Victor Lavy, and Sefi Roth. 2016. “The Long Run Economic Consequences of High-Stakes Examinations: Evidence from Transitory Variation in Pollution.” American Economic Journal: Applied Econ., 8(4):36-65.

Ganguli, Mary. 2015. “Cancer and Dementia: It's Complicated.” Alzheimer Disease and Associated Disorders, 29(2): 177-182.

Garen, John. 1984. "The Returns to Schooling: A Selectivity Bias Approach with a Continuous Choice Variable.” Econometrica, 52(5): 1199-1218.

Gatz Margaret et al. 1997. "Heritability for Alzheimer's Disease: The Study of Dementia in Swedish Twins.” J Gerontol A Biol Sci Med Sci., 52(2):M117-M125

Grande, Giulia, Petter L.S. Ljungman, Kristina Eneroth et al. 2020. “Association Between Cardiovascular Disease and Long-term Exposure to Air Pollution With the Risk of Dementia.” JAMA Neurology. 77(7):801-809.

Grainger, Corbett, and Andrew Schreiber. 2019 "Discrimination in Ambient Air Pollution Monitoring?." AEA Papers and Proceedings, 109, 277-82.

Graff-Zivin, Joshua and Matthew J. Neidell. 2013. "Environment, Health, and Human Capital.” Journal of Economic Literature 51(3): 689-730.

Hausman, Jerry A. 1978. “Specification Tests in Econometrics.” Econometrica, 46(6): 1251-1271.

Heckman, James J. 1979. “Sample Selection Bias as a Specification Error.” Econometrica, 47(1): 153-161.

Heckman James J. and Richard Robb. 1986. “Alternative Methods for Solving the Problem of Selection Bias in Evaluating the Impact of Treatments on Outcomes.” In: Wainer H. (eds) Drawing Inferences from Self-Selected Samples. Springer, New York, NY

Iaccarino, Leonardo et al. 2021. “Association Between Ambient Air Pollution and 
Amyloid Positron Emission Tomography Positivity in Older Adults With Cognitive Impairment.” JAMA Neurology. 78(2):197-207.

Isen, Adam, Maya Rossin-Slater and W. Reed Walker. 2017. "Every Breath You Take- Every Dollar You'll Make: The Long-Term Consequences of the Clean Air Act of 1970”. Journal of Political Economy, 125(3): 849-909.

Jeffery, Molly Moore. 2015. “A New Method for Identifying the Primary Care Treatability of Emergency Department Visits in a Medicare Population.” Ph.D. Dissertation. University of Minnesota.

Kang, You Jung, Hsih-Yin Tan, Charles Y Lee and Hansang Cho. 2021. “An Air Particulate Pollutant Induces Neuroinflammation and Neurodegeneration in Human Brain Models.” Advanced Science 8: 1-13.

Kulick, Erin R., Mitchell S.V. Elkind, Amelia K. Boehme et al. 2020. “Long-term exposure to ambient air pollution, APOE- $\varepsilon 4$ status, and cognitive decline in a cohort of older adults in northern Manhattan.” Environment International. 136: 105440 .

Lee, David S. 2009. "Training, Wages, and Sample Selection: Estimating Sharp Bounds on Treatment Effects.” Review of Economic Studies, 76: 1071-1102.

Lee, Eunjung et al. 2019. "Evaluation of Medicare Claims Data as a Tool to Identify Dementia.” Journal of Alzheimer's Disease. 67: 769-778.

Li, Jing, Yifan Wang, Kyle Steenland et al. 2022 "Long-term effects of PM2.5 components on incident dementia in the northeastern United States.”

Li, Shanjun, Nicholas Sanders, Guang Shi and Gong Yazhen. 2019. “The Mortality Impact of Fine Particulate Matter in China.” Working Paper.

McMillan, Robert and Joshua Murphy. 2017. "Measuring the Effects of Severe Air Pollution: Evidence from the UK Clean Air Act of 1956.” Working Paper.

Mortamais, Marion, Laure-Anne Gutierrez, Kees de Hoogh et al. 2021. “ Longterm exposure to ambient air pollution and risk of dementia: Results of the prospective Three-City Study.” Environmental International, 148: 106376.

Nevo, Aviv, and Adam M. Rosen. 2012. "Identification with Imperfect Instruments." Review of Economics and Statistics 94.3: 659-671.

Park, Christina, Anjum Hajat, Cindy S. Leary et al. 2021. "Associations between long-term air pollution exposure and plasma amyloid beta in very old adults." Alzheimer's \& Dementia. 17(Supp. 5):e054700.

Peters, Ruth et al. 2019. “Air Pollution and Dementia: A Systematic Review.” Journal of Alzheimer's Disease, 70: S145-S163.

Ran, Jinjun, C. Mary Schooling, Lefei Han et al. 2021. "Long-term exposure to fine particulate matter and dementia incidence: A cohort study in Hong Kong.” Environmental Pollution. 271:116303. 
Ridge, Perry G., Kaitlyn B Hoyt, Kevin Boehme et al. 2016. “Assessment of the genetic variance of late-onset Alzheimer's disease.” Neurobiology of Aging. 41: 200.e13-e20.

Rivers, Douglas and Quang H. Vuong. 1988. "Limited Information Estimators and Exogeneity Tests for Simultaneous Probit Models.” Journal of Econometrics, 39: 347-366.

Schlenker, Wolfram and W. Reed Walker. 2016. “Airports, Air Pollution, and Contemporaneous Health.” Review of Economic Studies, 83(2): 768-809

Shi, Liuhua, Xiao Wu, Mahdieh Danesh Yazdi et al. 2020. "Long-term effects of $\mathrm{PM}_{2.5}$ on neurological disorders in the American Medicare population: a longitudinal cohort study.” The Lancet, 4:e557-e565.

Shi, Liuhua, Kyle Steenland, Haomin Li et al. 2021. “A national cohort study (2000-2018) of long-term air pollution exposure and incident dementia in older adults in the United States.” Nature Communications. 12:6754

Shin, Su H., Dean R. Lillard, and Jay Bhattacharya (2019). “ Understanding the Correlation Between Alzheimer's Disease Polygenic Risk, Wealth, and The Composition of Wealth Holdings.” NBER working paper 25526.

Underwood, Emily. 2017. “The Polluted Brain”. Science. 355(6323): 342-345.

US Environmental Protection Agency. 2005. “Air Quality Designations and Classifications for Fine Particles (PM2.5) National Ambient Air Quality Standards; Final Rule”. Federal Registrar. 40 CFR Part 81. January 5, 2005.

Wang, Xinhui, Diana Younan, Joshua Millstein et al. 2022. “Association of improved air quality with lower dementia risk in older women.” PNAS 119(2):18.

Wilker, Elissa H., et al. 2015. "Long-term Exposure to Fine Particulate Matter, Residential Proximity to Major Roads and Measures of Brain Structure." Stroke, 46:1161-66.

Wooldridge, Jeffery. 2015. "Control Function Methods in Applied Econometrics,” Journal of Human Resources, 50(2): 420-445.

World Health Organization. 2011. International Statistical Classification of Diseases and Related Health Problems. 10th Rev. Vols. I-III. Geneva: World Health Organization.

Younan D et. al. 2020. "Women's Health Initiative. $\mathrm{PM}_{2.5}$ associated with gray matter atrophy reflecting increased Alzheimer's risk in older women.” Neurology. Nov 18. Available online: https://pubmed.ncbi.nlm.nih.gov/33208540/ .

Zhang, Xin, Xi Chen, and Xiaobo Zhang. 2018. "The Impact of Exposure to Air Pollution on Cognitive Performance.” Proc. of the Nat. Academy of Sciences, 115 (37) 9193-9197. 